Florida International University FIU Digital Commons

\title{
Investigation of Group Leadership in a Fission- Fusion Species, the Bottlenose Dolphin
}

Jennifer S. Lewis

Florida International University, jennifer.lewis1@fiu.edu

DOI: $10.25148 /$ etd.FI10081203

Follow this and additional works at: https://digitalcommons.fiu.edu/etd

\section{Recommended Citation}

Lewis, Jennifer S., "Investigation of Group Leadership in a Fission-Fusion Species, the Bottlenose Dolphin" (2010). FIU Electronic Theses and Dissertations. 254.

https://digitalcommons.fiu.edu/etd/254 


\section{FLORIDA INTERNATIONAL UNIVERSITY \\ Miami, Florida}

\section{INVESTIGATION OF GROUP LEADERSHIP IN A FISSION-FUSION SPECIES,}

THE BOTTLENOSE DOLPHIN

A dissertation submitted in partial fulfillment of the

requirements for the degree of

DOCTOR OF PHILOSOPHY

in

BIOLOGY

by

Jennifer Susan Lewis

2010 
To: Dean Kenneth G. Furton

College of Arts and Sciences

This dissertation, written by Jennifer Susan Lewis, and entitled Investigation of Group Leadership in a Fission-Fusion Species, the Bottlenose Dolphin, having been approved in respect to style and intellectual content, is referred to you for judgment.

We have read this dissertation and recommend that it be approved.

Michael Heithaus

Maureen Donnelly

Bennett Schwartz

Daniel Odell

Douglas Wartzok, Major Professor

Date of Defense: July 16, 2010

The dissertation of Jennifer Susan Lewis is approved.

\begin{tabular}{r}
\hline $\begin{array}{c}\text { Dean Kenneth G. Furton } \\
\text { College of Arts and Sciences }\end{array}$ \\
\hline Interim Dean Kevin O'Shea \\
University Graduate School
\end{tabular}

Florida International University, 2010 


\section{DEDICATION}

To my mom

Laissez Les Bon Temps Roulez 


\section{ACKNOWLEDGMENTS}

Completion of this work would not have been possible without the help of many people and resources. Starting with my advisers, I would first like to thank Dr. Dan Odell. An excellent source of advice and wisdom, I will always be grateful for your willingness to support me through all my hair-brained schemes.

To Dr. Schwartz who was the best possible outside committee member. I have appreciated your insights and your enthusiasm for my work. Your fantastic sense of humor has kept my spirits up throughout the toughest parts of this long process.

To Dr. Donnelly who gave me tough love by always letting me have it when I needed to have it (remember when I convinced everyone to audit a class? ... By the way Mike was the one who suggested it), but always looked out for my very best interests. Your unconditional support (and honest friendship) means the world to me, and I am honored to have had the chance to really get to know you over these years at FIU.

To Dr. Heithaus, who has contributed significantly towards my knowledge of behavioral ecology. I have always been impressed with your work and feel lucky to have had the chance to spend time with you, soaking up as much as I could. You have been incredibly giving of your time and your knowledge, and for that I will be forever grateful.

And finally, to my major adviser Dr. Wartzok, who allowed me to believe that you thought I could do everything I set out to do. That unconditional support gave me the confidence to make it happen every time (from filming under a helium airship to learning how to collect biopsies). While allowing me the space to try, you also challenged me to think critically about what I write and how I interpret the science I do. I am the last of the 
official Wartzok Mohicans. I hope that I have been a good end to the long list of students who have benefited from your advice and support.

Special thanks to Dr. Gerald Regan, who gave me my first break working on necropsies at Springhill College. Your enthusiasm for the field of science continues to inspire me.

Thanks to all of the countless volunteers who shared a great adventure with me. Especially the Unicorns (Jordin Blair, Katharine Becker and Christina Escalante), Mile Zero (Tanya Lubansky), Kitty (Sandra Lopez) the family von Trapp (Alësha Naranjit), Lisa Chandler, Tabitha Hui, Jessica Cusick and the balloon gang (Tayla Hackett, Shimpei Yamamoto, Mike Nemeth, and Justine Jackson-Ricketts).

I thank my super best friends, Laura May-Collado, Josette La Hee, Zayda Halun, and Brian Sidoti who made me laugh so many times. We have traveled over a crazy seven years together (and survived). I am so grateful that I got to do it with all of you. You ARE the girls (and guy) from SATC.

To my husband Dave I cannot say enough. You have always been in my corner and pushed me to keep moving. To never stop dreaming. I am so lucky to get to live life and all that comes with it with you. My best friend forever.

Thanks also to my family, who have been wondering for a very long time now when I would finally finish school. Answer = now.

A special thanks to the people of Key West who have supported my work for many years, including the Albrecht's and all the wonderful people at Key West Marina and NOAA Key West who gave me in-kind use of facilities, shared knowledge and expertise and provided great friendship. 
To the folks at NOAA Pascagoula, MS; NOAA Beaufort, SC and NOAA Virginia Key, FL who provided in-kind support and training for biopsy collection, I am grateful for all your help. I especially thank Dr. Keith Mullin (NOAA Pascagoula, MS) who allowed me to conduct this work, and Tony Martinez (NOAA Virginia Key, FL) for guidance and training.

I thank the Evolutionary Genetics Group of the University of Zürich, Switzerland for lab equipment, support and training which allowed me to conduct the genetic work included in this dissertation.

Finally, I thank the sources of financial support for this project which included grants through Sigma Xi, Project Aware, The American Society of Mammalogy, the Animal Behavior Society, Harbor Branch Oceanographic Institute, and the FIU Marine Biology Program. Fellowships through Florida International University (the Dissertation Acquisition Fellowship and the Dissertation Year Fellowship), allowed me to complete the final two semesters of field and lab work, and then the final year of analysis and writing of this dissertation. 


\title{
ABSTRACT OF THE DISSERTATION \\ INVESTIGATION OF GROUP LEADERSHIP IN A FISSION-FUSION SPECIES, THE BOTTLENOSE DOLPHIN
}

\author{
by \\ Jennifer Susan Lewis \\ Florida International University, 2010 \\ Miami, Florida \\ Professor Douglas Wartzok, Major Professor
}

Consistent leadership of group travel by specific individuals has been documented in many animals. Most species exhibiting this type of leadership have relatively stable group membership. Animals using fission-fusion grouping are not expected to use specific leaders because associations would not be frequent. Certain conditions, however, may allow this type of control over group travel to occur. First, a population would need to be small enough to allow regular associations between individuals. Second, leadership may be useful if the environment where the population in question lives is complex and requires learning to access the resources efficiently. To determine whether fission-fusion species existing under these conditions utilize specific individual leadership, I examined a small residential population of bottlenose dolphins (Tursiops truncatus) in the Lower Florida Keys (LFK) where the benthic habitat is highly complex. My goals were to 1) determine whether specific individuals in this population led group travel more often than expected; 2) determine whether certain factors predicted which animals would lead most often and 3) investigate the benefits of leading to leaders and to followers in a 
fission-fusion society. Multiple types of data were collected to answer questions posed including dolphin behavior (for leadership analyses), fish sampling (to examine dolphin habitat use under leadership), and dolphin biopsy sampling (for genetic analyses). Results of analyses provided strong evidence for consistent leadership in this population. Leaders were female, most were mothers and on average they had larger measures of centrality within the LFK population. Leaders benefited by leading individuals who were more closely related than expected. Followers benefited from efficient access to profitable habitat. Results build on previous leadership research by expanding our knowledge about the type of species in which specific individuals lead and predictors for what types of individuals may lead. Additionally, results provide the first detailed information about benefits group members obtain by both leading and following. 


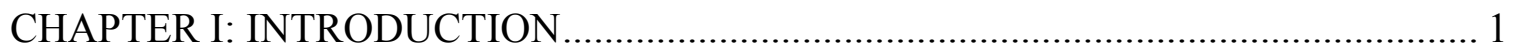

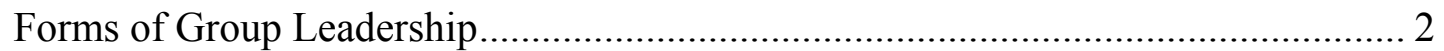

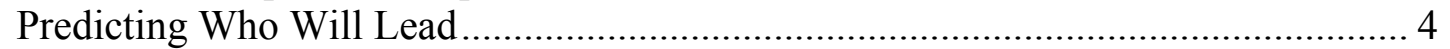

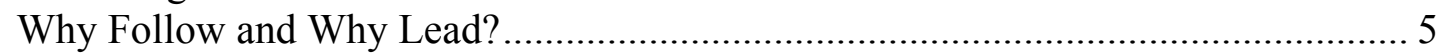

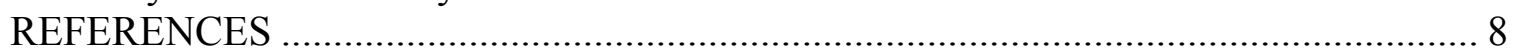

CHAPTER II: HIGHLY DYNAMIC FISSION-FUSION SPECIES CAN EXHBIT

LEADERSHIP WHEN TRAVELING ………………..................................... 10

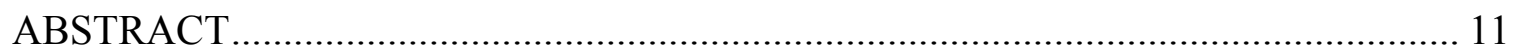

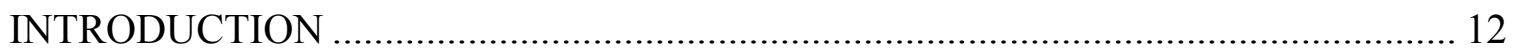

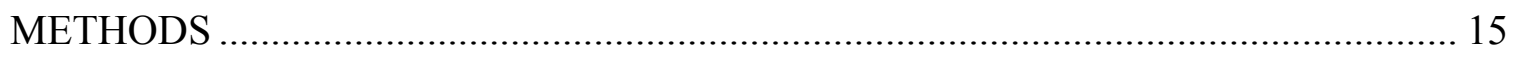

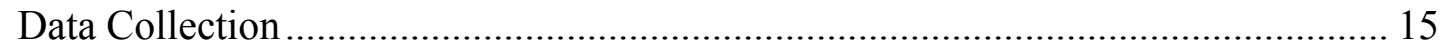

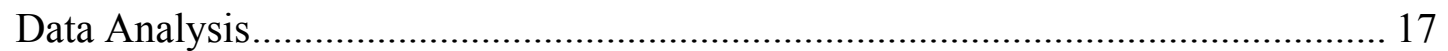

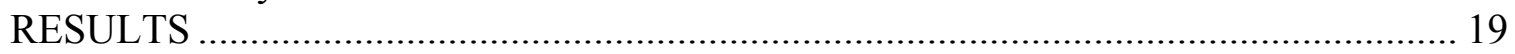

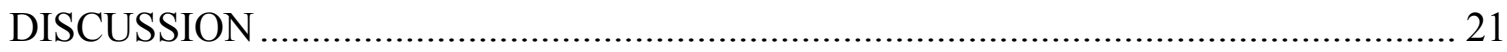

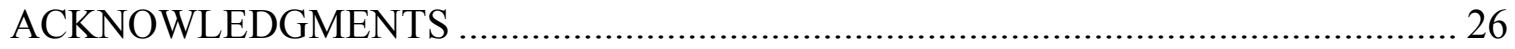

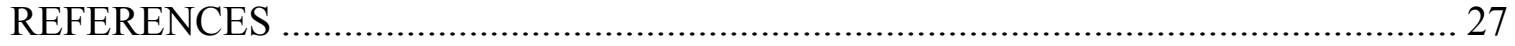

CHAPTER III: PREDICTORS OF LEADERSHIP IN FISSION-FUSION GROUPS OF

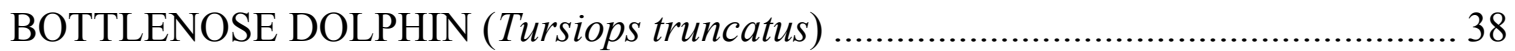

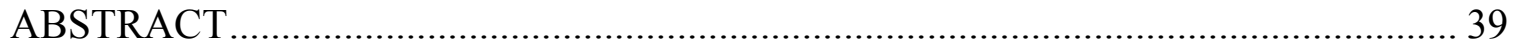

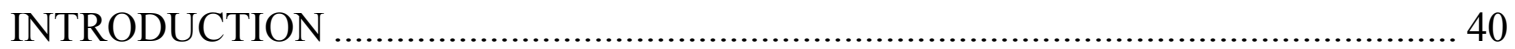

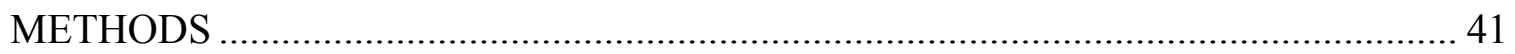

Gender, Kinship and Reproductive State ……………............................................ 41

Social Network Placement.............................................................................. 43

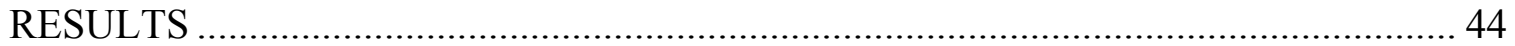

Gender, Kinship and Reproductive State ............................................................. 44

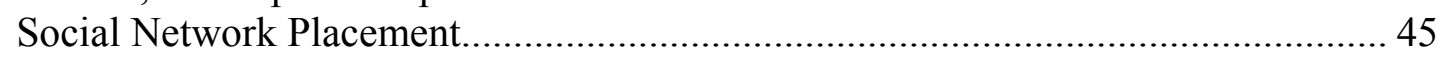

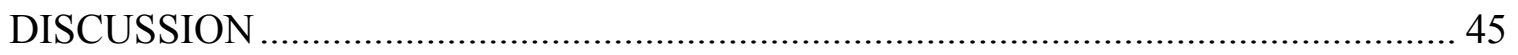

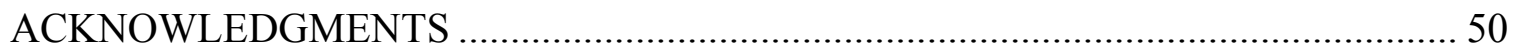

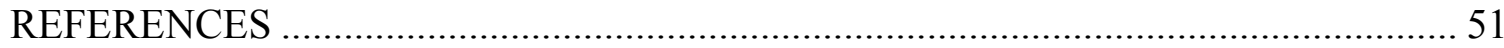

CHAPTER IV: LEADERSHIP PROVIDES BENEFITS TO FOLLOWERS IN

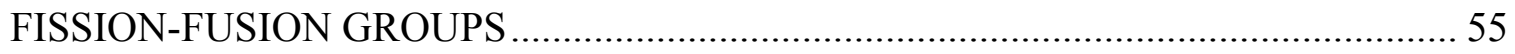

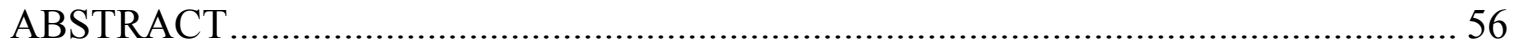

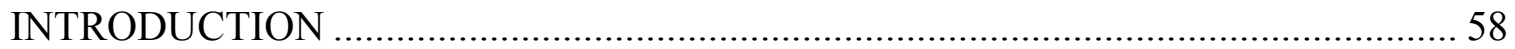

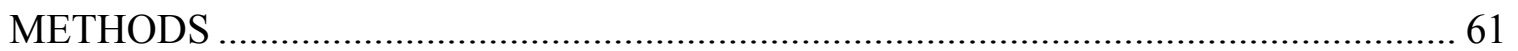

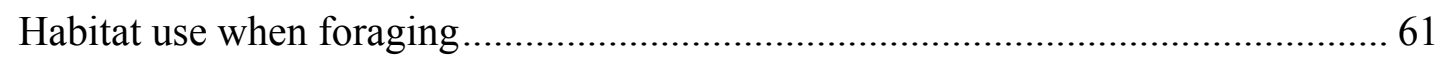

Area use by leaders and followers........................................................................ 64

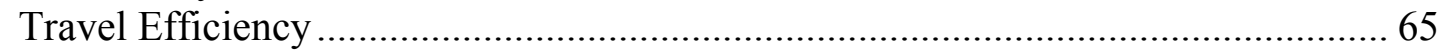

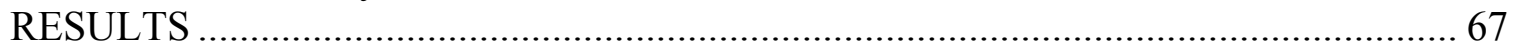

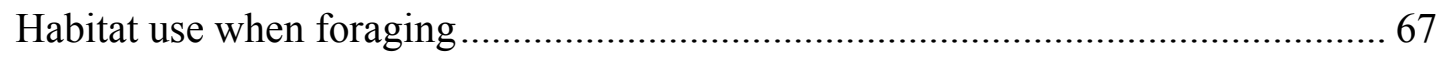




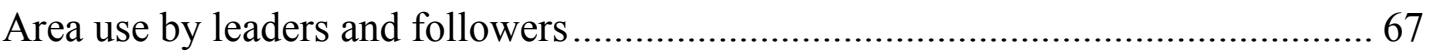

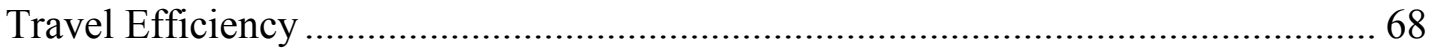

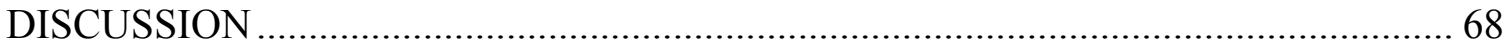

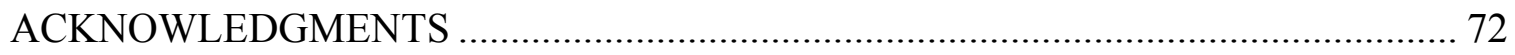

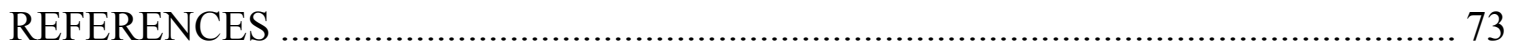

CHAPTER V: INCLUSIVE FITNESS BENEFITS OF GROUP LEADING IN

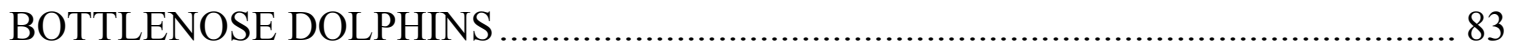

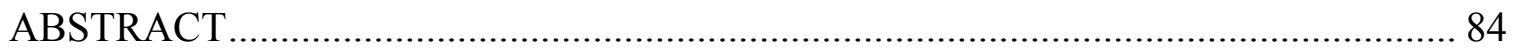

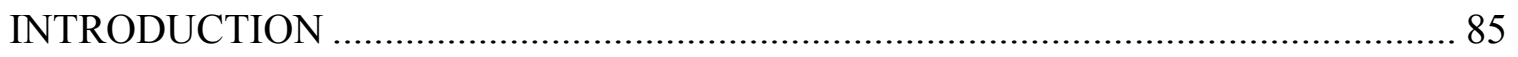

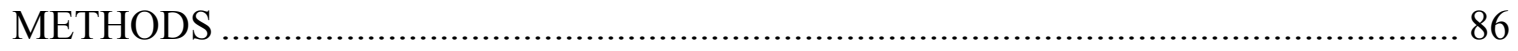

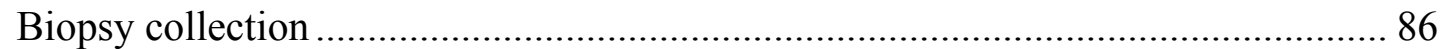

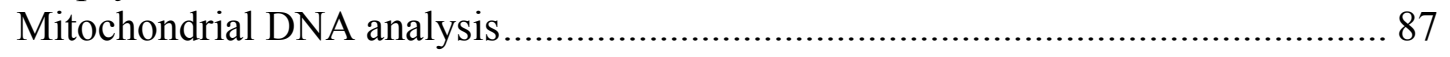

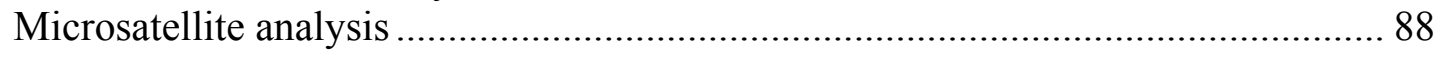

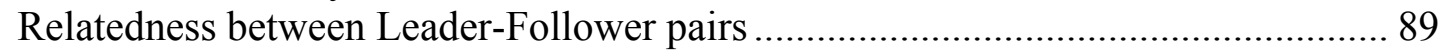

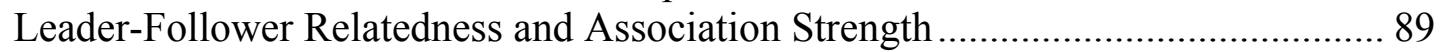

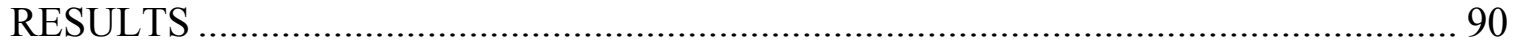

Relatedness between Leader-Follower Pairs ....................................................... 90

Leader-Follower Relatedness and Association Strength ..................................... 90

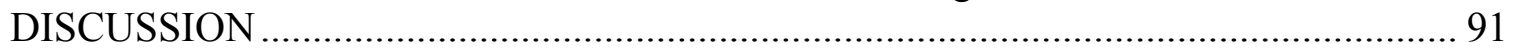

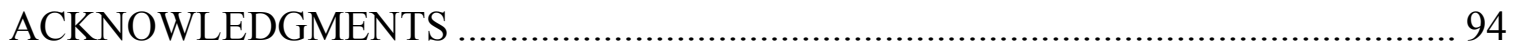

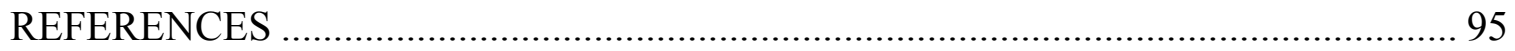

CHAPTER VI: CONCLUDING REMARKS .................................................... 101

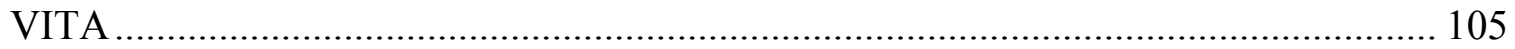




\section{LIST OF FIGURES}

FIGURE

PAGE

Figure 1. Lower Florida Keys research area. Zones within the study area include all navigable waters.

Figure 2.A Floatograph ${ }^{\circledR}$ airship (a) was used to mount a video camera (b) for continuous monitoring of dolphin behavior. The airship was tethered to the research vessel and towed during surveys and group follows.

32 and 33

Figure 3. Measures for time spent leading by individuals. These preliminary analyses allowed determination of leadership threshold to be used in each group sampling. (a) The number of individuals that led groups for different fractions of time during the first 30 minutes of 104 follows and (b) The number of individuals with various average proportions of leadership across the first 5 follows/individual ( $\mathrm{n}=52$ individuals). Bars representing the number of individuals that were $<20 \%$ of all observations are colored black for each graph. Black bars in both graphs represent greater than the majority of observations for each comparison (69\% and 63\% respectively).

Figure 4. The number of follows where individual dolphins spent more than $20 \%$ of the follow in the lead position. Data are from the first 13 follows for each individual. Individuals that led significantly more than expected based on chance are labeled $(*)$. All animals leading more than expected had $P<0.008$.

Figure 5. Example of a frequency histogram generated by randomizations $(\mathrm{n}=$ 1000 iterations) to test for greater than expected leadership by dolphin 057 . The observed value is indicated with an arrow

Figure 6. Number of successful and unsuccessful direction change attempts by leading and following bottlenose dolphins.

Figure 7. Measures of centrality for leaders and followers in dolphin groups in the Lower Florida Keys, (LFK) FL. (a) Betweenness values for dolphins in the LFK. (b) Degree values for LFK dolphins. Leaders are represented by black bars, followers include all other bars and are divided according to gender $($ dark gray $=$ female, light grey $=$ unknown and white $=$ male $)$. All leaders are female. Lines indicate the level for the lowest measure for leaders 
Figure 8. Map of benthic habitats in Man of War Harbor (circled in black). 76

Figure 9. Relative biomass of fish available to dolphins in the Lower Florida Keys in three available habitats, (SU = Shallow Unvegetated, SV = Shallow Vegetated and DC $=$ Deep Channel)

Figure 10. Probability of encounter for leader-led and follower-led groups in Man of War Harbor (MOW) benthic habitats (shallow vegetated and deep channel), and variation in benthic biomass available in LFK habitats (SU = Shallow Unvegetated, SV = Shallow Vegetated, DC = Deep Channel). Only shallow vegetated and deep channel habitats were available in MOW. Shallow vegetated habitat has more potential biomass of dolphin prey $($ mean $=95.1 \mathrm{~g} / \mathrm{hr}, \mathrm{SD}=95.5)$, compared to deep channel habitat (mean $=$ $76.6 \mathrm{~g} / \mathrm{hr}, \mathrm{SD}=121.0)$

Figure 11. Association between length of foraging bouts and group size for bottlenose dolphins in the Lower Florida Keys $(n=41, r s=-0.34, p=$ $0.009)$.

Figure 12. Frequency distribution for mean number of distinct areas within an individual home range ( $95 \%$ fixed kernel contour), created by random permutations of the actual data set for dolphins in the waters of the Lower Florida Keys (LFK), Florida. Distinct areas were defined as being separated by impassible area (by land or extreme shallows). LFK leaders (defined as having led groups more often than expected based on chance, Lewis, Chapter I), had more distinct areas within their home ranges than expected based on chance.

Figure 13. Mean number of changes in vanguard animal (black bars) and in path directness (grey bars) for leader led (L) and follower led (F) dolphin groups when traveling.

Figure 14. Association between number of changes in vanguard animal, and directness of paths taken when traveling for bottlenose dolphin groups $(\mathrm{n}=$ $86, \mathrm{r}=-0.33, \mathrm{p}=0.0001)$

Figure 15. Frequency of pair-wise relatedness values (Queller and Goodnight 1989) for leader-follower pairs (black bars) and for all pairs that were sampled (gray bars). 
Figure 16. Association Index values (Half-Weight Index) plotted against relatedness values (Queller and Goodnight 1989) for leader -follower dolphin pairs in the Lower Florida Keys $(\mathrm{rs}=0.55, \mathrm{p}<0.002)$. 100 
CHAPTER I: INTRODUCTION 
Early observations of primate travel processions and how leadership decisions were negotiated within them (e.g., DeVore and Washburn 1963; Rowell 1969; Kummer 1971) sparked continued interest in the study of leadership. Today the field has expanded to include topics ranging from predicting how leadership is manifested in groups (e.g., King and Cowlishaw 2009; Bonanni et al., 2010; Conradt and Roper 2010) to modeling the forces that maintain accurate travel (e.g., Couzin et al., 2005; Mireabet et al., 2008; Rands et al., 2008). Despite growing interest in the field, many aspects of leadership remain unstudied. In this dissertation, my objective was to add to knowledge about leadership, through study of a fission-fusion species, where leadership was not generally expected, (Fischoff et al., 2007), but ecological conditions might provide the opportunity for its use. The purpose of this chapter is to provide a general introduction to research on leadership and to outline how my studies build on our current knowledge of this subject.

\section{Forms of Group Leadership}

Leadership involves decision making that directs group behavior. These decisions can range from rule making that aids group organization to guidance in travel direction. How decisions are made within groups can vary, ranging from full group participation (shared consensus: Conradt and Roper 2005) to despotism, where one or few individuals control choice (e.g., wolf packs: Peterson et al., 2003). Combinations of the two can also exist, where individuals can choose to allow a subset to make decisions for them. Shared consensus decision making is expected to occur when needs vary between group members (Conradt and Roper 2010). As fission-fusion group formation is based on variation in individual needs, fission-fusion type species are not expected to demonstrate 
consistent leading by specific individuals (Fischoff et al., 2007). However, under certain conditions, consistent leading by specific individuals may still be possible. One major hindrance for consistency in leading is the ability for specific individuals in a fissionfusion society to interact on a regular basis. But, regular interaction can occur in relatively small residential populations. More importantly, for leadership to emerge in such a society there must be benefits to followers that result from following specific individuals. Environmental complexity where substantial learning is necessary, may provide the impetus for consistent leading by specific individuals to develop.

In Chapter II, I examine whether consistent leading by specific individuals occurs in a population of a highly dynamic fission-fusion species (changing complete group composition frequently over hours or days), the bottlenose dolphin (Tursiops truncatus), found in the Lower Florida Keys, (LFK). Several characteristics of this population suggest that specific leaders might be used. First, the LFK population is small and residential, so interactions among specific individuals are frequent, allowing assessment of individual capacity and ability to lead. Secondly, the habitat in the LFK is extremely heterogeneous, with usable areas divided by large expanses of impassible areas (e.g., shallows or islands) suggesting that individual experience may vary among dolphins. Individual dolphins may then differ in the efficiency with which they use habitat (i.e., some individuals will be better leaders than others). On the basis of these conditions, I predicted that dolphins of the LFK should be capable of identifying good leaders, and that following individuals with greater knowledge about how to best access profitable areas, may be important in the LFK. Therefore, leading by consistent individuals might be expected. 


\section{Predicting who will lead}

Following early studies demonstrating leadership, focus shifted towards determining the type of individual more likely to lead in a particular society (e.g., Rowell 1969; Kummer 1971; Dunbar and Dunbar 1971). Given the diverse taxonomic and ecological conditions under which leadership has been documented, it is not surprising that the type of individual leading varied considerably between species. Both females and males were documented as consistent leaders (e.g., females: lemurs, Erhart and Overdorff 1999; mongoose, Rasa 1987, males: howler monkey, Milton 2000; chacma baboon, Rhine et al., 1985). In many cases where specific individuals lead, these individuals were also dominant (e.g., capuchins, Di Bitetti and Janson 2001; wolves, Peterson et al., 2003). Other factors investigated included physiological state, experience and personality. Controlled experiments determined that hungrier individuals were more likely to lead under some conditions (Krause et al., 1993; Rands et al., 2003) and that experience (Levin 1996; Reebs 2000) and exploratory nature (Beauchamp 2000) may play a role in leadership dynamics. Finally, knowledge about the location of resources has been suggested as driving which individuals lead in groups (Lusseau and Conradt 2009; King and Cowlishaw 2009).

Investigation of factors associated with leadership have focused on species where group membership is fairly stable (i.e., group membership is relatively unchanging over time). In Chapter III of this dissertation I examine potential predictors of who leads. Because group membership changes frequently and dominance hierarchies are unlikely in dolphins of the LFK, there is no a priori expectation that one gender would be more likely to lead than the other. 
However, energetic demands can influence leadership (e.g., Krause et al., 1993; Rands et al., 2003), so I examined gender and reproductive state (females with calf or without calf).

Enhanced knowledge of habitats and resources are a potential basis for leadership. Multiple communities exist across the LFK. Communities are defined as individuals that interact frequently with one another (frequency ranging from daily to monthly), and share space use ( $>50 \%$ of home range). Documenting associations of leaders with individuals in more than one community would indicate a greater scope of area familiarity for leaders (if followers do not do the same). Measures of centrality within a social network can provide information about how individuals are positioned within their social network through connections to subgroups within a population (e.g., communities). If leaders are central within the LFK social network, then they likely have more associates, and groups of these associates are connected to one another only through links to leaders (Croft et al., 2008). In Chapter III, I used social network analysis to determine if and how network positions differed between leaders and followers.

\section{Why Follow and Why Lead?}

Central to the dynamics of leadership are the relative costs and benefits of leading and following. Studies mindful of leader costs and benefits have focused on increased access to resources through location prior to other group members for leaders (i.e., "finders share": Di Bitetti and Janson 2001; Barelli et al., 2008). Benefits to followers cited include access to resources through greater knowledge held by leaders (e.g., Lusseau and 
Conradt 2009; King and Cowlishaw 2009) and increased concentration on tasks other then travel decision making (Piyapong et al., 2007).

In fission-fusion societies, individuals have the choice to follow, or to head out on their own with the possibility that others will choose to follow them. To consistently follow specific individuals under this type of grouping indicates that benefits are greater when following leaders, either through increased access to resources or through decreased energy expenditure when searching. Increased access to resources may be provided by leaders who have greater knowledge about profitability of habitat types and who are familiar with more areas that can be used for foraging. Decreased energy expenditure may be provided if leader led groups travel more directly when moving through habitat between foraging locations. In Chapter IV, I investigate what benefits are provided to followers by 1) comparing leader-led to follower-led groups to determine whether they differed in habitat use according to prey availability, 2) comparing home range characteristics (size and number of distinct areas within) between leaders and followers to determine if leaders had the ability to provide access to more area, and 3) comparing travel directness and number of lead animal changes when traveling for leader led and follower led groups to test travel efficiency.

Studies of leader benefits have focused on species with non-motile prey (fruit and leaves) (Di Bitetti and Janson 2001; Barelli et al., 2008). Bottlenose dolphins in the LFK, however, forage on prey that are mobile, patchy and generally do not occur in large schools (Lewis, personal observation). As a result, group members have equal probability of locating a fish to consume. Without the "finders share" to offset the costs of tolerating followers, the question remains "why lead?" One possibility is that leaders are providing 
benefits to relatives. In Chapter V, I test this hypothesis by examining whether leaders are related to their followers. 


\section{REFERENCES}

Barelli, C., Boesch, C., Heistermann, M., \& Reichard, U. H. (2008). Female whitehanded gibbons (Hylobates lar) lead group movements and have priority of access to food resources. Behaviour, 145(12), 965.

Beauchamp, G. (2000). Individual differences in activity and exploration influence leadership in pairs of foraging zebra finches. Behaviour, 137(3), 301-314.

Bonanni, R., Cafazzo, S., Valsecchi, P., \& Natoli, E. (2010). Effect of affiliative and agonistic relationships on leadership behaviour in free-ranging dogs. Animal Behaviour,

Conradt, L., \& Roper, T. J. (2005). Consensus decision making in animals. Trends in Ecology \& Evolution, 20(8), 449-456.

Conradt, L., \& Roper, T. J. (2010). Deciding group movements: Where and when to go. Behavioural Processes,

Couzin, I. D., Krause, J., Franks, N. R., \& Levin, S. A. (2005). Effective leadership and decision-making in animal groups on the move. Nature, 433, 513-516.

Croft, D. P., James, R., \& Krause, J. (2008). Exploring animal social networks Princeton University Press.

DeVore, I., \& Washburn, S. L. (1963). Baboon ecology and human evolution. African Ecology and Human Evolution, 335-367.

Di Bitetti, M. S., \& Janson, C. H. (2001). Social foraging and the finder's share in capuchin monkeys, Cebus apella. Animal Behaviour, 62(1), 47-56.

Erhart, E. M., \& Overdorff, D. J. (1999). Female coordination of group travel in wild Propithecus and Eulemur. International Journal of Primatology, 20(6), 927-940.

Fischhoff, I. R., Sundaresan, S. R., Cordingley, J., Larkin, H. M., Sellier, M. J., \& Rubenstein, D. I. (2007). Social relationships and reproductive state influence leadership roles in movements of plains zebra, Equus burchellii. Animal Behaviour, $73(5), 825-831$.

Giraldeau, L. A., \& Caraco, T. (2000). Social foraging theory Princeton University Press.

King, A. J., \& Cowlishaw, G. (2009). Leaders, followers and group decision-making. Communicative and Integrative Biology 2, 147-150. 
Krause, J. (1993). The relationship between foraging and shoal position in a mixed shoal of roach (Rutilus rutilus) and chub (Leuciscus cephalus): A field study. Oecologia, 93(3), 356-359.

Kummer, H. (1971). Primate societies Aldine-Atherton Chicago.

Levin, L. E. (1996). Passage order through different pathways in groups of schooling fish, and the diversified leadership hypothesis. Behavioural Processes, 37(1), 1-8.

Lusseau, D., \& Conradt, L. (2009). The emergence of unshared consensus decisions in bottlenose dolphins. Behavioral Ecology and Sociobiology, 63(7), 1067-1077.

Mirabet, V., Fréon, P., \& Lett, C. (2008). Factors affecting information transfer from knowledgeable to naive individuals in groups. Behavioral Ecology and Sociobiology, 63(2), 159-171.

Peterson, R. O., Jacobs, A. K., Drummer, T. D., Mech, L. D., \& Smith, D. W. (2002). Leadership behavior in relation to dominance and reproductive status in gray wolves, Canis lupus. Canadian Journal of Zoology, 80(8), 1405-1412.

Rands, S. A., Cowlishaw, G., Pettifor, R. A., Rowcliffe, J. M., \& Johnstone, R. A. (2003). Spontaneous emergence of leaders and followers in foraging pairs. Nature, 423(6938), 432-434.

Rands, S. A., Cowlishaw, G., Pettifor, R. A., Rowcliffe, J. M., \& Johnstone, R. A. (2008). The emergence of leaders and followers in foraging pairs when the qualities of individuals differ. BMC Evolutionary Biology, 8, 51.

Rasa, O. A. E. (1987). The dwarf mongoose: A study of behavior and social structure in relation to ecology in a small, social carnivore. Advances in the Study of Behavior, 17, 121-163.

Reebs, S. G. (2000). Can a minority of informed leaders determine the foraging movements of a fish shoal? Animal Behaviour, 59(2), 403-409.

Rhine, R. J., Bioland, P., \& Lodwick, L. (1985). Progressions of adult male chacma baboons (Papio ursinus) in the Moremi wildlife reserve. International Journal of Primatology, 6(2), 115-122.

Rowell, T. (1969). Long-term changes in a population of Ugandan baboons. Folia Primatologica, 11(4), 241-254. 
CHAPTER II: HIGHLY DYNAMIC FISSION-FUSION SPECIES CAN EXHBIT LEADERSHIP WHEN TRAVELING 


\begin{abstract}
Leadership by specific individuals is thought to enhance the fitness of group members by allowing them to take advantage of the knowledge or skills of key individuals. In general, consistent leadership is expected to occur primarily in stable groups of related individuals where the benefits enhance the inclusive fitness of a leader. Societies with less stability in group composition (i.e., fission-fusion groups) are less likely to feature unshared decision making. However, in situations where frequent interactions among individuals occur (e.g., small population size and small range of movement) and/or the complexity of the environment requires substantial experience and knowledge, consistent leadership might be expected. I tested if a highly dynamic fission-fusion society of bottlenose dolphins (Tursiops truncatus) inhabiting a complex environment exhibited leadership when traveling. A small number of specific individuals led group travel more often than expected by chance, and were more likely to initiate successful direction changes of groups than following individuals. The number of leaders in a group remained relatively constant across a wide range of group sizes and was not affected by the number of potential leaders (i.e., those that had led previously) present in the group. Together these results suggest that leadership can occur in highly dynamic fission-fusion societies and loss of key individuals could have disproportionate effects on population dynamics.
\end{abstract}

Key words: Bottlenose dolphin, decision making, fission-fusion, group movement, group size, keystone individual, leadership, Tursiops truncatus 


\section{INTRODUCTION}

Unraveling the costs and benefits of group formation has been a primary goal of behavioral biologists, resulting in studies across a wide range of taxa and ecological conditions (see Krause and Ruxton 2002). Less work has focused on the relative contributions of specific individuals to the success of groups and to individuals in them. This perspective is important because individual contributions to foraging, reproductive success, and survival of group members can be divided unequally, either through proportion of time engaged or through variation in tactics used (e.g., producer/scrounger dynamics: Caraco and Giraldeau 1991; "keystone individuals”, Sih and Watters 2005).

Leadership, "where one or a few individuals steer the behavior of many” (King et al. 2009) also results in variation in group member contribution. For some species direction of travel is guided primarily by a small number of individuals (e.g., Erhart and Overdorff 1999; Reebs 2000; Peterson et al. 2002; Stueckle and Zinner 2008). As a result, these 'leaders' contribute disproportionately to the relative success of other group members because they guide them to or away from profitable resources (e.g., Conradt and Roper 2005; Fischhoff et al. 2007). For example, in African elephants (Loxodonata sp.) matriarchs appear to provide leadership for group travel (Payne 2003). Memory of water sources (sometimes in locations not visited in over a year's time) by matriarchs appears to be responsible for the relative success of this species compared to others during severe droughts (Viljoen 1990; Payne 2003). In species where group membership is relatively unchanging over time (e.g., gray wolves, Canis lupus, Peterson et al. 2002) followers must abide by the leader's decisions in order to maintain group stability (i.e., 
"unshared consensus decision making" Conradt and Roper 2005). However, in fissionfusion societies where group composition and size changes frequently, individuals can select the group size, and potentially the specific group, that will maximize their fitness. Although fission-fusion societies exhibit considerable variation in the organization level and rate at which groups change in size and composition, in highly dynamic fissionfusion societies (i.e., high rates of change) interactions with the same individuals will be less frequent than in societies with stable groups. Therefore, consistent leadership by a restricted set of individuals should be less likely (Fischhoff et al. 2007). Such consistent leadership by specific individuals has been described primarily in species with relatively stable groups characterized by a dominance hierarchy (e.g., capuchins, Cebus sp., Di Bitetti and Janson 2001; gray wolves, Peterson et al. 2002). However, there may be situations where dynamic fission-fusion societies might also demonstrate consistent leadership. For example, in complex habitats where resources are not easy to locate or navigation among habitats could be dangerous without adequate experience and understanding (e.g., risk of predation or starvation), knowledgeable individuals may consistently lead groups even if group composition is unstable. Additionally, individuals in some fission-fusion populations (i.e., those with small population size, restricted individual ranges, and small group sizes) interact frequently with other individuals providing an opportunity for individuals to identify effective leaders. Anecdotal evidence suggests that leadership when traveling does occur in some fission-fusion species: e.g., African elephants (Payne 2003), spider monkeys, Ateles sp., (Milton 2000). However, formal testing has yet to provide conclusive evidence for specific individual leadership, particularly in highly dynamic fission-fusion species. 
Bottlenose dolphins (Tursiops sp.) are an example of a dynamic fission-fusion species that have demonstrated individual recognition (e.g., Connor et al. 2001). Recent work in Doubtful Sound, New Zealand on bottlenose dolphins has indicated that specific individual bottlenose dolphins may influence activity shifts through slapping the water surface ("side flops" and "lobtailing") (Lusseau and Conradt 2009). This finding suggests that in bottlenose dolphins specific individuals have the capacity to influence movement of group members. However, it remains unclear whether this finding extends to other bottlenose dolphin populations and whether specific individuals influence group movement during travel.

The population of bottlenose dolphins inhabiting the heterogeneous coastal habitats of the Lower Florida Keys (LFK), USA offers a model system for examining these questions. First, the complexity of the area provides an impetus for use of knowledgeable individuals as leaders. The LFK is composed primarily of shallow waters (average depth $\sim 2 \mathrm{~m}$, range $.5-10 \mathrm{~m}$ ) with both vegetated (seagrass) and unvegetated regions (sand or hard bottom), bifurcated by deeper channels (range 4-10m). Diurnal tides are small in magnitude (0.15-0.3m) but affect fish (Sogard et al. 1989) and dolphin movement (Lewis and Schroeder 2003) because changes in water depth modify the accessibility of, and ability to safely traverse, large areas of shallow habitat. Second, study of individuals within groups is possible in the LFK because the population is small $(\sim 150-200)$ and residential, and features small group sizes (Mean $=4.4 \pm 3.3 \mathrm{SD}$, Lewis 2002) and easily recognized individuals. LFK dolphins are characterized by a high rate of 
fission-fusion (Mean $=54 \pm 23 \mathrm{~min}$ SD between changes in group composition; unpublished data), such that the composition of all groups in this study was different.

I used the LFK population to test: 1) if certain individuals led by position (i.e., front of the group) more often than expected; 2) if positional leaders controlled direction change more often than positional followers (to determine if control was correlated with position); and 3) whether factors including group size and number of potential leaders contributed to the number of individuals that led a group.

\section{METHODS}

\section{Data collection}

Dolphins were located during surveys $(n=238)$ from a $5 \mathrm{~m}$ Open Fisherman with an 110hp outboard between October 2001 and September 2007 in the LFK (Fig. 1). Surveys followed pre-determined routes along smaller zones within the study area (Fig. 1) traveling at approximately $22 \mathrm{~km} / \mathrm{hr}$. One to four zones were covered each survey day (depending on weather conditions). Surveys occurred primarily (>95\%) in zones 1, 2, 4 and 5 for the current study because dolphin sightings are more frequent in those areas. Survey routes allowed complete observation of all navigable waters within these zones. Surveys were only conducted under Beaufort wind conditions of three or less. When dolphins were located, I initiated continuous data collection of group members (Altmann 1974). I defined different groups (varying in composition from one another) to be my sampling units, and refer to these as "group samples". During my study I collected 171 group samples ( $>1$ individual). Individual dolphins were identified using unique patterns of nicks and cuts on their dorsal fins (Würsig and Würsig 1977). I recorded the relative 
positions of all individuals when animals surfaced, direction change attempts by all animals (change in heading estimated at $>35^{\circ}$ ) and success of the attempts (i.e., other groups members followed the new heading). It was possible to collect data on individual dolphins in LKF groups, especially the identity of individuals in the front position of groups, because group sizes are small (see above) and fins are easily identifiable. Group size and composition were continuously monitored during sampling. Groups were defined as all animals within approximately $100 \mathrm{~m}$ that likely were interacting, (i.e., traveling in the same direction, socializing and maintaining proximity when foraging) (Shane 1990). Group fission was considered a physical separation (generally considered when over 100m apart) of previously grouped individuals who were no longer interacting (i.e., no longer traveling, socializing or foraging together). This definition was useful for my particular study, because dolphins in the LFK tend to travel in different directions when fission occurs (personal observation). Also the multiple islands and shallows ( $<$ $0.3 \mathrm{~m}$ ) that divide areas where the LFK dolphins live hinders vocal communication as dolphins move apart. When fissions occurred, I maintained sampling with the portion of the group that contained the individual that had previously been in the front position during group travel.

Because my data included relative positions of individuals during surfacing events, it was important to verify whether surfacing positions corresponded to subsurface travel. This was done using an overhead video camera (Sony $\left.{ }^{\circledR} \mathrm{CD} 52 \mathrm{~W}\right)$ mounted below a tethered airship (Floatograph ${ }^{\circledR}$ ) (Fig. 2). Pan, tilt and zoom of the lens mounted below the airship were controlled on board the vessel where video was displayed on a monitor and 
recorded to DVD. Because waters of the Florida Keys are relatively clear (visibility averages ca. $6 \mathrm{~m}$ ) the overhead camera allowed continuous viewing of dolphins across most of my study area. I collected positional data for 41 individuals in 17 groups (15 hours of footage) using the airship. Footage was reviewed using The Observer ${ }^{\circledR}$ (Noldus Information Technology).

\section{Data Analysis}

I used two methods to define a threshold level for the time spent in the front position that could be considered as "leading" for each group sampled. These methods were used not to test explicitly for consistent leadership by specific individuals, but to identify a threshold for classifying individuals during a particular group sample as assuming a greater proportion of time in the lead position than is typical (i.e., calling a dolphin a 'leader' during a particular group sampling). Using this threshold for leadership during a group sampling, I could then investigate if particular individuals led during more group samples than would be expected by chance (i.e., displayed "consistent leadership" across group samples). Methods for determining this within-group sample threshold for leadership included 1) comparing the number of individuals that led for different total proportions of surfacing events during the first $30 \mathrm{~min}$ of each group sample (Bins used: $0 \%,>0$ to $10 \%,>10 \%$ to $20 \%$, etc.), and 2 ) comparing the average leadership values between individuals that had been sampled at least 5 times ( $n=47$ individuals). Using individuals who had been sampled at least 5 times provided me with a representative group that included $47 \%$ of all individuals sampled. 
Using the within-group sample leadership threshold (20\% of group sample duration in lead position; see Results), I examined if specific individuals exhibited leadership during more group samples than would be expected by chance. Data used included only the part of a group sample prior to any fission or fusion event (if one occurred during that group sample). I employed a randomization protocol (Manly 2006) using data from 20 individuals. These individuals were chosen based on sample size requirements per individual (power analysis, $\beta>.80$ ). I compared the number of times each individual led $\geq 20 \%$ of a group sample to the number expected based on 1000 randomization iterations for each individual (i.e., a test was performed for each individual). For each iteration, I randomly reallocated the observed proportions of time individuals spent in the lead among all group samples of the twenty individuals tested. I then determined the number of times the focal individual was in the lead position of a group sample $\geq 20 \%$ of the time based on the randomizations. I compared my field observations to the distribution of expected number of group samples that individuals were a leader and considered an individual to consistently be a leader if the field observation was greater than $97.5 \%$ of the randomizations $(P<0.05$ for a two-tailed test).

To determine if positional leaders controlled group movement, I examined factors affecting the probability of successfully changing the direction of a group's travel (defined as having other group members follow the new heading). Using logistic regression (Tabachnick and Fidell 1996) I tested whether position within a group (i.e., lead position or following), group size, or number of participating leaders influenced the 
probability of successfully changing the direction of a group's travel. No individuals were used more than once in this test.

To examine how the number of leaders in a group (leading defined using threshold) was affected by group size, I used Theil's regression (Daniel 1990). We included only adults, because calves could not be potential leaders and did not move ahead of group members when traveling. Number of leaders was also compared pre and post fission and fusion (using Wilcoxon tests). To determine whether the number of leaders per group differed from the number available I used a Wilcoxon sign rank test. Available leaders used were those that had led (according to our threshold of leadership) during the year of the group sample tested. Finally, I examined the number of leaders per group sample to the length of the group sample to determine if sample length affected the number of leaders noted (Spearman Rank Correlation).

\section{RESULTS}

Using video collected from the airship, I found no significant differences between the proportion of time individuals spent in the lead position of a group (both surface and subsurface observations) and the proportion of time in lead position by those individuals based only on surfacing events (Wilcoxon paired sign rank test: $z=-0.28, P=0.77$ ). Thus, relative positions of individuals during surfacing bouts reflect total time spent in lead positions.

The majority of individuals (69\%) spent $<20 \%$ of the time leading during the first 30min of all group samples (Fig. 3). Seventy percent of all individuals also had average leadership values that were $<20 \%$ (Fig. 3). Because both methods indicated that the 
majority of individuals spend $<20 \%$ of their time leading, I established $20 \%$ as the threshold for an individual to be classified as a leader for a specific group sample.

The Monte Carlo simulation showed that three of the 20 individuals tested led during more group samples than expected based on chance (Fig. 4; see Fig. 5 for an example). These individuals led $\geq 20 \%$ during the majority of all group samples where they were present (proportion of group samples where individuals led ranged from 77\% to $84 \%)$.

The probability of initiating a successful direction change was influenced by the position of the individual (leader vs. follower) $\left(\chi^{2}=22.52\right.$, $\mathrm{df}=1, P=0.0001$ ) but not by group size $\left(\chi^{2}=0.52, \mathrm{df}=1, P=0.47\right)$ or the number of leaders in the group $\left(\chi^{2}=0.49\right.$, $\mathrm{df}=1, P=0.49)$. Leaders made more attempts at changing direction and were more successful than followers ( $88 \%$ of 26 leader attempts, compared to $38 \%$ of 13 follower attempts) (Pearson Chi-Square: $\chi^{2}=18.59, \mathrm{df}=1, P<0.0001$ ) (Fig. 6).

The number of individuals in a group that led during a group sample remained constant over all group sizes (slope $=0, \tau=0.13, P=0.06)$. Total number of leaders per group sample never exceeded three, and most group samples had only one ( $46 \%$ of group samples) or two (44\% of group samples) leaders. The number of leaders did not change significantly after fission (Wilcoxon Test: $P>0.999$ ) or fusion (Wilcoxon Test: $z=-0.78$, $P=0.44)$

The number of participating leaders (Mean $=1.61 \pm 0.61 \mathrm{SD})$ was significantly lower than the number of potential leaders in a group (Mean $=3.75 \pm 2.39 \mathrm{SD})$, (Wilcoxon 
Test: $z=-8.474, P<0.0001, n=122$ ) and the number of leaders did not vary with the length of time that a dolphin group was sampled (Spearman Rank Test: $r_{s}=0.12, t=$ $1.37, n=131, P=0.17)$.

\section{DISCUSSION}

My findings indicate that most individual bottlenose dolphins in the Lower Florida Keys spend little time leading group movement, but a small number of individuals consistently spend a significant amount of time in the lead position. This small subset of leading individuals was disproportionately responsible for the direction of group travel; they controlled group movement through position and success at direction change. Together, these results provide the first evidence for leadership by specific individuals when traveling in a highly dynamic fission-fusion society.

To date, consistent leadership when traveling has been documented primarily in societies with stable group composition (e.g., Rasa 1987, Peterson et al. 2002). Such leadership roles tend to coincide with dominance hierarchies (Peterson et al. 2002;

Fischhoff et al. 2007; King et al. 2008; Jacobs 2008). In non-hierarchical groups, leaders tend to be those in need of a specific resource (i.e., "diversified leadership", Levin 1996; or "leading according to need", Conradt et al. 2009). Hungrier animals will start traveling first and because others within the group tend to follow these movements, they will travel in the direction established by the leader (Šárová et al. 2007; Barelli et al. 2008). Under "diversified leadership", the animal in the lead can vary from travel point to travel point and the individual in front changes frequently with no consistency in leader identity over time. Because the composition of groups changes frequently, and is often based on the 
particular needs and behavioral state of individuals, animals in fission-fusion societies would be expected to follow a particular individual for relatively short periods of time, but specific individuals should not consistently be found in the lead position (Fischhoff et al. 2007).

Certain conditions are likely necessary for consistent leadership by specific individuals in highly dynamic fission-fusion societies. These may include a complex environment or spatiotemporal variation in resource abundance and/or predictability that require significant learning for efficient movement. Leadership may be important for LFK dolphins because of the heterogeneous and complex nature of the marine habitat in this region. Seagrass flats and unvegetated shallow water basins are surrounded by many large stretches (ranging from $\sim 1$ to $\left.20 \mathrm{~km}^{2}\right)$ of extremely shallow water $(<0.5 \mathrm{~m})$ that are not accessible at low tides. Many expanses of productive shallow habitats are accessible only via a handful of deeper channels. Because some areas can only be accessed or traversed during high tides, and others are only accessible via few deeper channels, mistakes regarding movement paths could lead to stranding or a loss of foraging opportunities. Therefore, dolphins without sufficient experience would benefit by following others with greater knowledge.

Particular features of a fission-fusion population may also help to determine if specific individuals will consistently lead group movements. Leadership by specific individuals on a repeated basis requires frequent and regular interaction among the same individuals so that followers can identify effective leaders. Therefore populations would need to be small, form small groups, with individuals inhabiting small and stable home 
ranges. The LFK population exhibits all of these features. Some bottlenose dolphin populations with fission-fusion dynamics, may be less likely to exhibit consistent leadership because of large population sizes (e.g., Mississippi Sound, Hubard 1998), long-distance migrations (e.g., Atlantic Coast United States, Barco et al. 1999; Wood 1998) large group sizes (e.g., Pacific Coast, United States, Defran and Weller 1998), or relatively predictable resources and easily navigable habitats (e.g., Shark Bay, Australia, Heithaus and Dill 2002).

Interestingly, in the LFK, the number of individual dolphins that led during a group sample remained low (never greater than three and usually only one or two) regardless of group size or length of group sample, even when multiple potential leaders were present. Because it only takes a few informed individuals to move a group accurately from one point to another (Couzin et al. 2005; Dryer et al. 2008), it is likely that having a low number of leaders per group provides a mechanism for more efficient travel (Conradt and Roper 2005). A low number of leaders may reduce chaos in decision making, wasting less time and energy.

Control of group movement varies within and among species (Overdorff et al. 2005; Fischhoff et al. 2007). In another closely related bottlenose dolphin species, Tursiops aduncus, in Shark Bay, Australia, male pairs and trios control movement of individual reproductively-cycling females through aggressive herding (Connor et al. 1992). I have not observed herding in LFK bottlenose dolphins. Instead, males usually interact reproductively with females in larger mixed-sex groups. Sexual activity in LFK groups usually occurs towards the rear of a group because the involved individuals are 
slower to progress. These individuals follow movement choices but do not initiate them. In Doubtful Sound, surface slapping (side flops and upside down lob tails) by bottlenose dolphins (Tursiops truncatus) initiates activity changes in groups (Lusseau and Conradt 2009). In the LFK, surface slapping occurs rarely, and only in a social context. Although these factors (herding or control of movement through surface impact behavior) did not contribute to control of movement in the LFK population, they need to be considered in studies of leadership for other dolphin populations. Indeed, results from Shark Bay, Doubtful Sound, and LFK suggest that specific individuals may disproportionately influence group activities and/or movements in multiple bottlenose populations.

The presence of leadership in the LFK population has important implications for conservation and management. LFK animals guiding movement may be 'keystone individuals' and potentially play an important role in the viability of the LFK population by shaping habitat use patterns and enhancing foraging opportunities for other individuals. When matriarchs in groups of African elephants (Loxodonta africana) are lost from the population, significant disruption can occur to the remaining group members, because these 'leaders' (Payne 2003) act as storehouses of critical social information that enable groups to manage time efficiently (McComb et al. 2001). Coastal dolphins are under pressure from many sources (e.g., contaminants, Litz et al. 2007, habitat alteration, Watson-Capps and Mann 2005, and vessel traffic, Nowacek et al. 2001) and although these stressors may not disproportionately affect leaders, my results suggest that the loss of specific individual dolphins (leaders) from the LFK population may have a greater proportional impact on the population than would be expected 
otherwise. Further investigations of the specific roles of leaders and the characteristics of individuals that are consistent leaders, therefore, should be a priority. 


\section{ACKNOWLEDGMENTS}

Financial support for this project came from Sigma Xi, Harbor Branch Oceanographic Institute, Florida International University Graduate Student Association and Project Aware. In-kind support was provided by the Florida Keys National Marine Sanctuary Office of Key West, Florida and the Key West City Marina of Key West, Florida. J. Lewis was supported in part during the writing of this manuscript by the Florida International University Dissertation Year Fellowship. We thank all volunteer interns who gave assistance in the field and in the lab, the U. S. Department of Transportation Federal Aviation Administration for allowing us to use the airspace around the island of Key West, Florida and finally Mote Marine Lab's Dolphin Biology Research Institute for

allowing us to view and analyze overhead footage of Sarasota, Florida dolphins for pilot analysis. Improvements in the manuscript were made thanks to helpful review by Dan Odell, Maureen Donnelly, Bennett Schwartz, Janet Mann and Brooke Sargeant. This research was conducted under NMFS Level B Letter of Confirmation No. 572-1639 and FIU IACUC No. 03-020. 


\section{REFERENCES}

Altmann, J. 1974. Observational study of behaviour: Sampling methods. Behaviour, 227267.

Barco, S. G., Swingle, W. M., Mclellan, W. A., Harris, R. N., \& Pabst, D. A. 1999. Local abundance and distribution of bottlenose dolphins (Tursiops truncatus) in the nearshore waters of Virginia Beach, Virginia. Marine Mammal Science, 15(2), 394408 .

Barelli, C., Boesch, C., Heistermann, M., and Reichard, U. H. 2008. Female whitehanded gibbons (Hylobates lar) lead group movements and have priority of access to food resources. Behaviour, 145(12), 965-981.

Caraco, T., and Giraldeau, L. 1991. Social foraging: Producing and scrounging in a stochastic environment. Journal of Theoretical Biology, 153(4), 559-583.

Connor, R. C., Smolker, R. A. and Richards, A. F. 1992. Two levels of alliance formation among bottlenose dolphins (Tursiops sp.). Proceedings of the National Academy of Sciences 89, 987-990.

Connor, R. C., M. R. Heithaus and L. M. Barre. 2001. Complex social structure, alliance stability and mating success in a bottlenose dolphin "super-alliance". Proceedings of the Royal Society B, Biological Sciences, 268, 263-267.

Conradt, L., and Roper, T. J. 2005. Consensus decision making in animals. Trends in Ecology \& Evolution, 20(8), 449-456.

Conradt, L., Krause, J., Couzin, I. D., and Roper, T. J. 2009. "Leading according to need" in self organizing groups. The American Naturalist, 173(3), 304-312.

Couzin, I. D., Krause, J., Franks, N. R., and Levin, S. A. 2005. Effective leadership and decision-making in animal groups on the move. Nature, 433, 513-516.

Daniel, W. W. 1990. Applied nonparametric statistics. PWS-Kent Publishing Boston, MA.

Defran, R. H. and Weller, D. W. 1998. Occurrence, distribution, site fidelity and school size of bottlenose dolphins (Tursiops truncatus) off San Diego, California. Marine Mammal Science 15, 366-380.

Di Bitetti, M. S. and Janson, C. H. 2001. Social foraging and the finder's share in capuchin monkeys, Cebus apella. Animal Behaviour 62, 47-56. 
Dyer, J. R. G., Ioannou, C. C., Morrell, L. J., Croft, D. P., Couzin, I. D., Waters, D. A. and Krause, J. 2008. Consensus decision making in human crowds. Animal Behaviour, 75, 461-470.

Erhart, E. M. and Overdorff, D. J. 1999. Female coordination of group travel in wild Propithecus and Eulemur. International Journal of Primatology, 20(6), 927-940.

Fischhoff, I. R., Sundaresan, S. R., Cordingley, J., Larkin, H. M., Sellier, M. J., and Rubenstein, D. I. 2007. Social relationships and reproductive state influence leadership roles in movements of plains zebra, Equus burchellii. Animal Behaviour, 73(5), 825-831.

Heithaus, M. R., and Dill, L. M. 2002. Food availability and tiger shark predation risk influence bottlenose dolphin habitat use. Ecology, 83(2), 480-491.

Hubard, C. W. 1998. Abundance, distribution, and site fidelity of bottlenose dolphins in Mississippi Sound, Mississippi. M.S. Thesis. University of Alabama, Tuscaloosa, AL. 101pp.

Jacobs, A. 2008. The influence of social organization on leadership in brown lemurs (Eulemur fulvus fulvus) in a controlled environment. Behavioural Processes, 79(2), 111-113.

King, A. J., Douglas, C. M. S., Huchard, E., Issac, N. J. B., and Cowlishaw, G. 2008. Dominance and affiliation mediate despotism in a social primate. Current Biology, 18(23), 1833-1838.

Krause, J., and Ruxton, G. D. 2002. Living in groups. Oxford University Press. New York, NY.

Levin, L. E. 1996. Passage order through different pathways in groups of schooling fish, and the diversified leadership hypothesis. Behavioural Processes, 37(1), 1-8.

Lewis, J. S. 2002. Behavioural comparison of two populations of the bottlenose dolphin (Tursiops truncatus) in Florida waters. M. S. Thesis, University of Alabama. Tuscaloosa, AL. 118pp.

Lewis, J., and Schroeder, W. 2003. Mud plume feeding, a unique foraging behaviour of the bottlenose dolphin (Tursiops truncatus) in the Florida Keys. Gulf of Mexico Science, 1, 92-97. 
Litz, J. A., Garrison, L. P., Fieber, L. A., Martinez, A., Contillo, J. P., and Kucklicks, J. R. 2007. Fine-scale spatial variation of persistent organic pollutants in bottlenose dolphins (Tursiops truncatus) in Biscayne Bay, Florida. Environmental Science and Technology, 41(21), 7222-7228.

Lusseau, D. and L. Conradt. 2009. The emergence of unshared consensus decisions in bottlenose dolphins. Behavioral Ecology and Sociobiology 63(7), 1067-1077.

Manly, B. F. J. 2006. Randomization, bootstrap and Monte Carlo methods in biology. Chapman \& Hall/CRC, Boca Raton, FL.

McComb, K., Moss, C., Durant, S. M., Baker, L., and Sayialel, S. 2001. Matriarchs as repositories of social knowledge in African elephants. Science, 292(5516), 491-494.

Milton, K. 2000. Quo vadis? Tactics of food search and group movement in primates and other animals. In: On the Move. Eds. S. Boinski and P. A. Garber. The University of Chicago Press. Chicago.

Nowacek, S. M., Wells, R. S., and Solow, A. R. 2001. Short-term effects of boat traffic on bottlenose dolphins, Tursiops truncatus, in Sarasota Bay, Florida. Marine Mammal Science, 17(4), 673-688.

Overdorff, D. J., Erhart, E. M. and Mutschler, T. 2005. Does female dominance facilitate feeding priority in black-and-white ruffed lemurs (Varecia variegata) in southeastern Madagascar? American Journal of Primatology 66, 7-22.

Payne, K. 2003. Sources of social complexity in the three elephant species. Animal Social Complexity: Intelligence, Culture, and Individualized Societies, Ed. by F. B. M. de Waal and P.L. Tyack, Harvard University Press, Cambridge, MA. pp.57-85.

Peterson, R. O., Jacobs, A. K., Drummer, T. D., Mech, L. D., and Smith, D. W. 2002. Leadership behaviour in relation to dominance and reproductive status in gray wolves, Canis lupus. Canadian Journal of Zoology, 80(8), 1405-1412.

Rasa, O. A. E. 1987. The dwarf mongoose: A study of behavior and social structure in relation to ecology in a small social carnivore. Advances in the Study of Behavior, $17,121-163$.

Reebs, S. G. 2000. Can a minority of informed leaders determine the foraging movements of a fish shoal? Animal Behaviour, 59, 403-409. 
Šárová, R., Špinka, M., and Panamá, J. L. A. 2007. Synchronization and leadership in switches between resting and activity in a beef cattle herd-A case study. Applied Animal Behaviour Science, 108(3-4), 327-331.

Shane, S. 1990. Behaviour and ecology of the bottlenose dolphin at Sanibel Island, Florida. The Bottlenose Dolphin, Ed. by S. Leatherwood and R. R. Reeves, Academic Press, San Diego, CA. 245-265.

Sih, A., and Watters, J. V. 2005. The mix matters: Behavioural types and group dynamics in water striders. Behaviour, 142, 9(10), 1417-1431.

Sogard, S. M., Powell, G. V. N., and Holmquist, J. G. 1989. Utilization by fishes of shallow, seagrass-covered banks in Florida Bay: 2. Diel and tidal patterns.

Environmental Biology of Fishes, 24(2), 81-92.

Stueckle, S. and Zinner, D. 2008. To follow or not to follow: Decision making and leadership during the morning departure in Chacma baboons. Animal Behaviour, 75(6), 1995-2004.

Tabachnick, B. G. and Fidell, L. 1996. Using multivariate statistics. HarperCollins, New York. NY.

Viljoen, P. J. 1990. Daily movements of desert dwelling elephants in the northern Namib Desert. South African Wildlife Research 20(2), 69-72.

Watson-Capps, J. J. and Mann, J. 2005. The effects of aquaculture on bottlenose dolphin (Tursiops sp.) ranging in Shark Bay, Western Australia. Biological Conservation, 124(4), 519-526.

Wood, C. 1998. Movement of bottlenose dolphins around the south-west coast of Britain. Journal of Zoology, 246(2), 155-163.

Würsig, B. and Würsig, M. 1977. The photographic determination of group size, composition, and stability of coastal porpoises (Tursiops truncatus). Science, 198(4318), 755-756. 


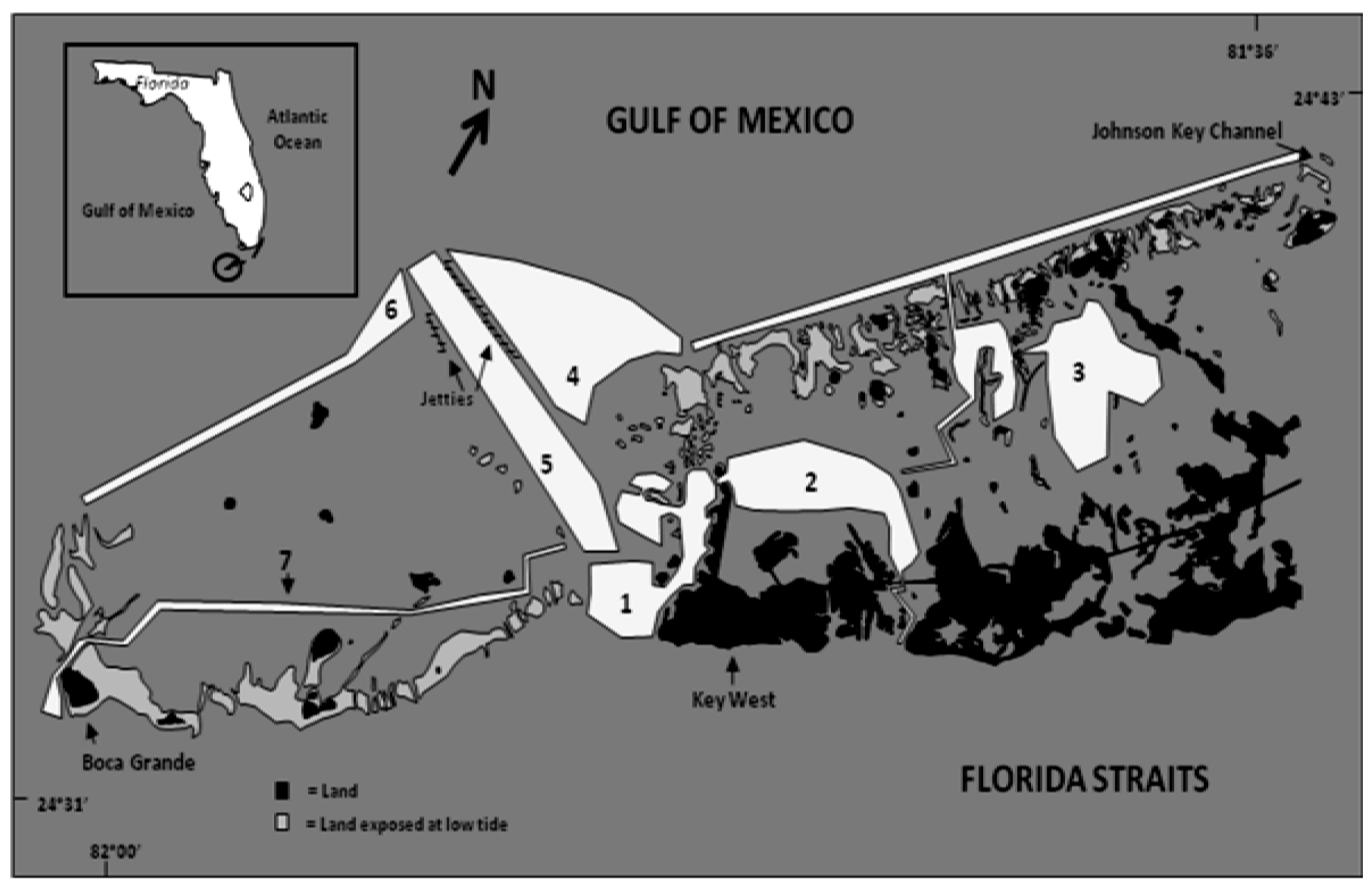

Figure 1. Lower Florida Keys research area. Numbered zones within the study area include all navigable waters. 


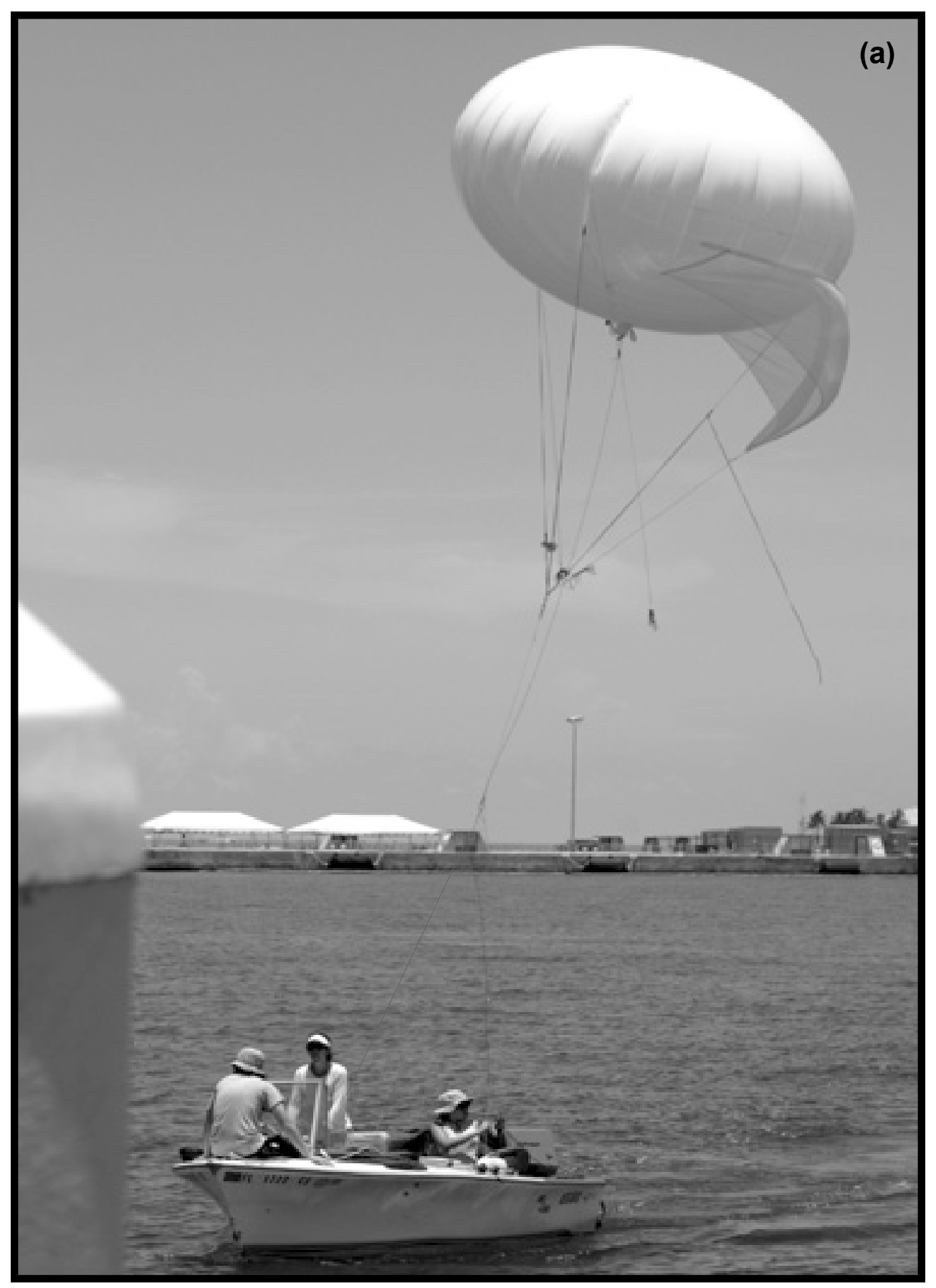

Figure 2. A Floatograph ${ }^{\circledR}$ airship, (a), was used to mount a video camera, (b), for continuous monitoring of dolphin behavior. The airship was tethered to the research vessel and towed during surveys and group sampling. 


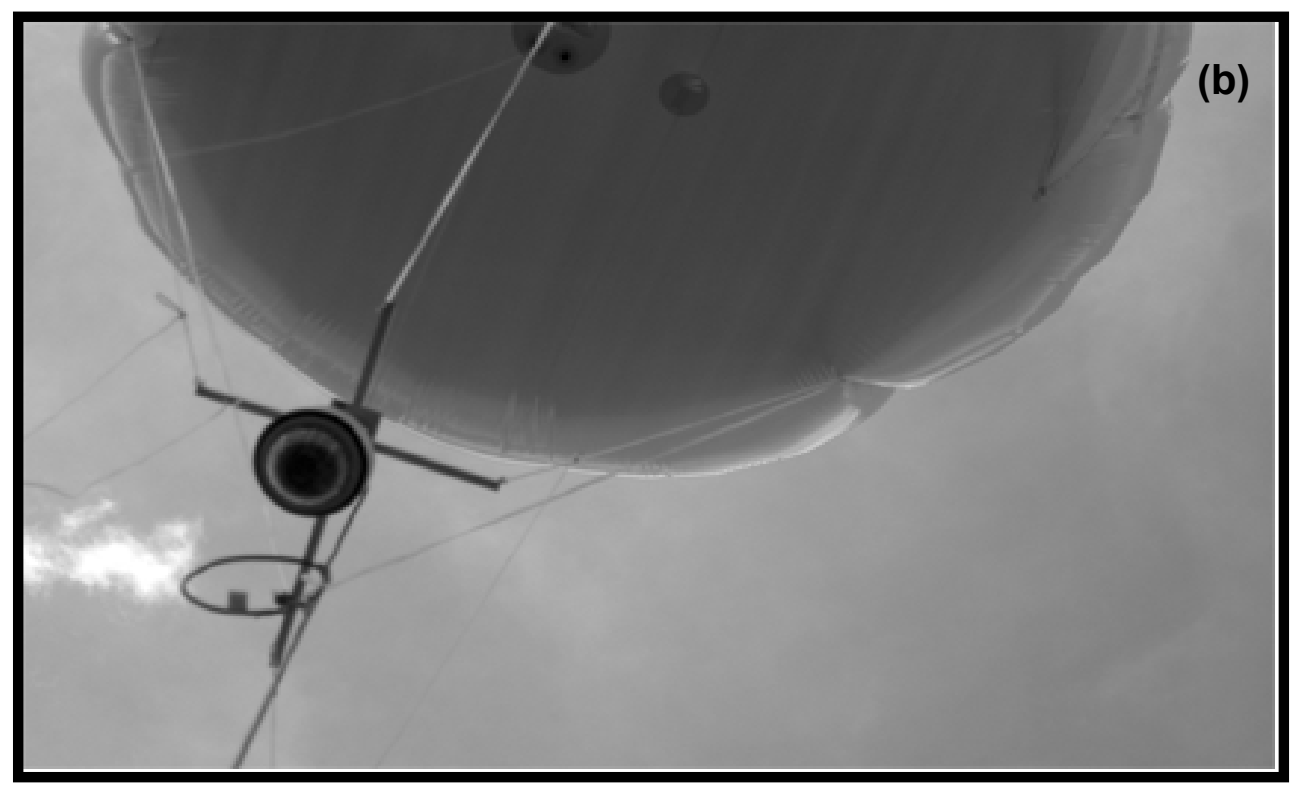

Figure 3. A Floatograph ${ }^{\circledR}$ airship, (a), was used to mount a video camera, (b), for continuous monitoring of dolphin behavior. The airship was tethered to the research vessel and towed during surveys and group sampling. 

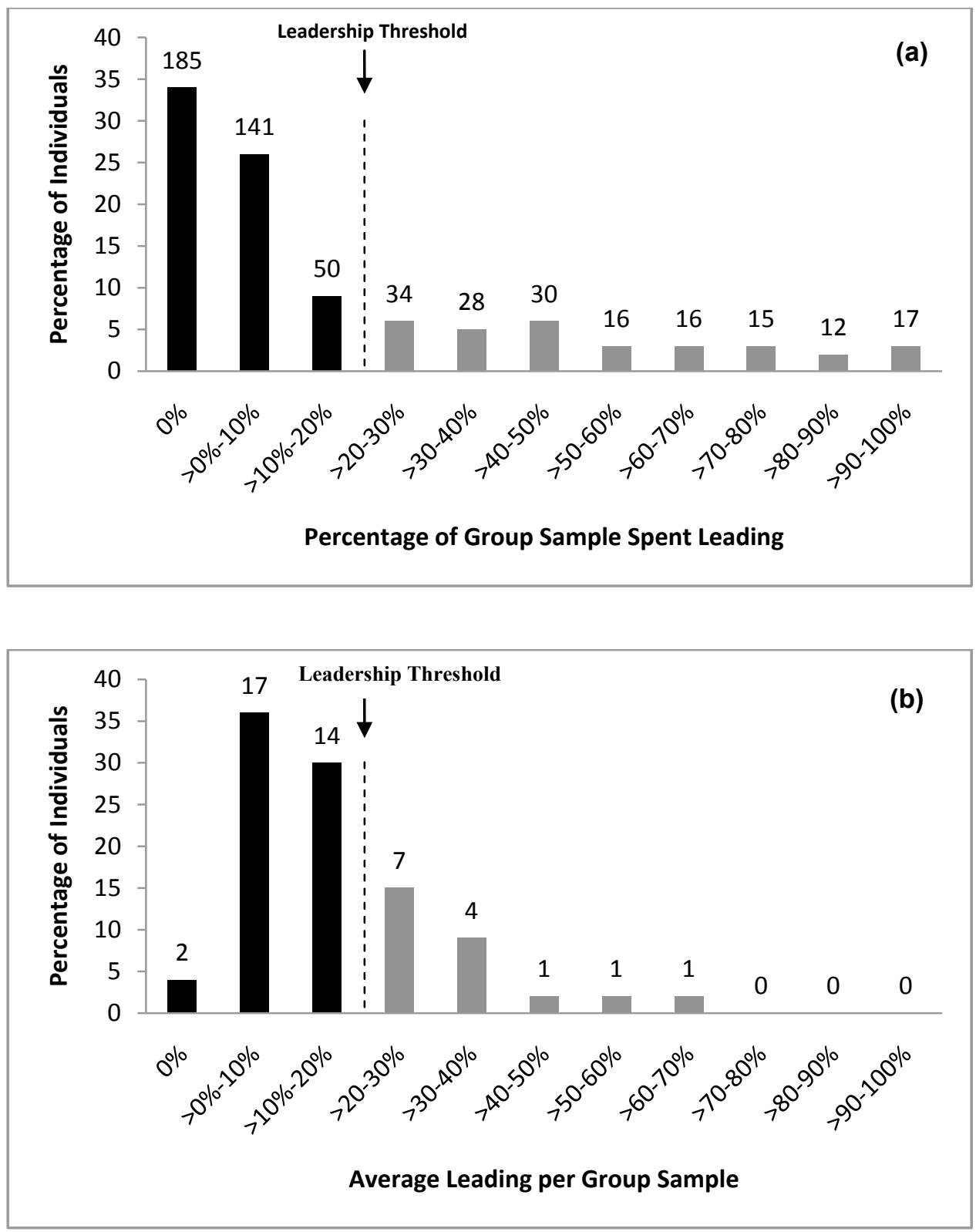

Figure 4. Measures for time spent leading by individuals. These preliminary analyses allowed determination of leadership threshold to be used in each group sampling. (a) The proportion of individuals that led groups for different percentages of time during the first 30 minutes of 104 group samples and (b) The proportion of individuals with various average time spent leading across group samples (individuals used had $\geq 5$ group samples, $n=47$ individuals). Bars representing the number of individuals that were $<20 \%$ of all observations are colored black for each graph. Black bars in both graphs represent greater than the majority of observations for each comparison (69\% and $70 \%$ respectively). Numbers above bars are the number of individuals. 


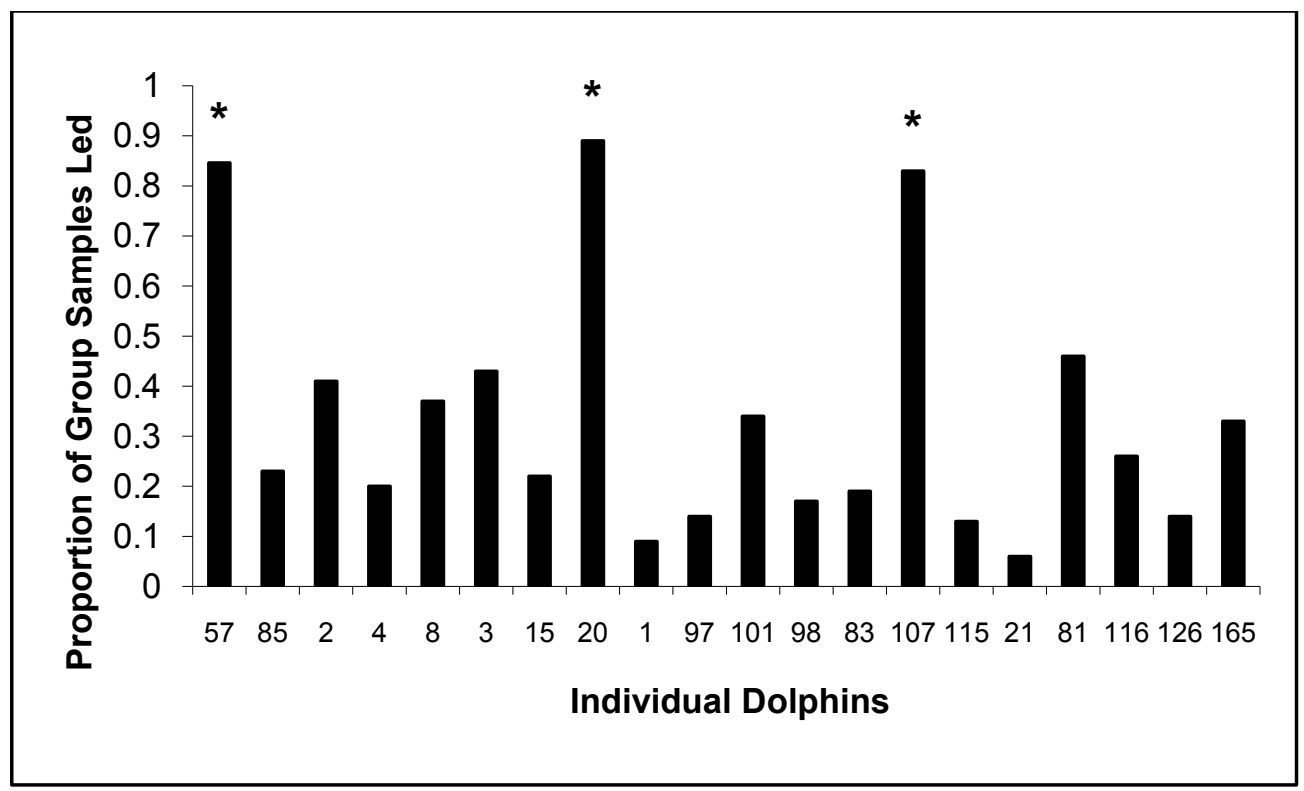

Figure 4. The proportion of group samples where individual dolphins spent more than $20 \%$ of the sample in the lead position. Individuals that led significantly more than expected based on chance are labeled $(*)$. All animals leading more than expected had $P<0.002$. 


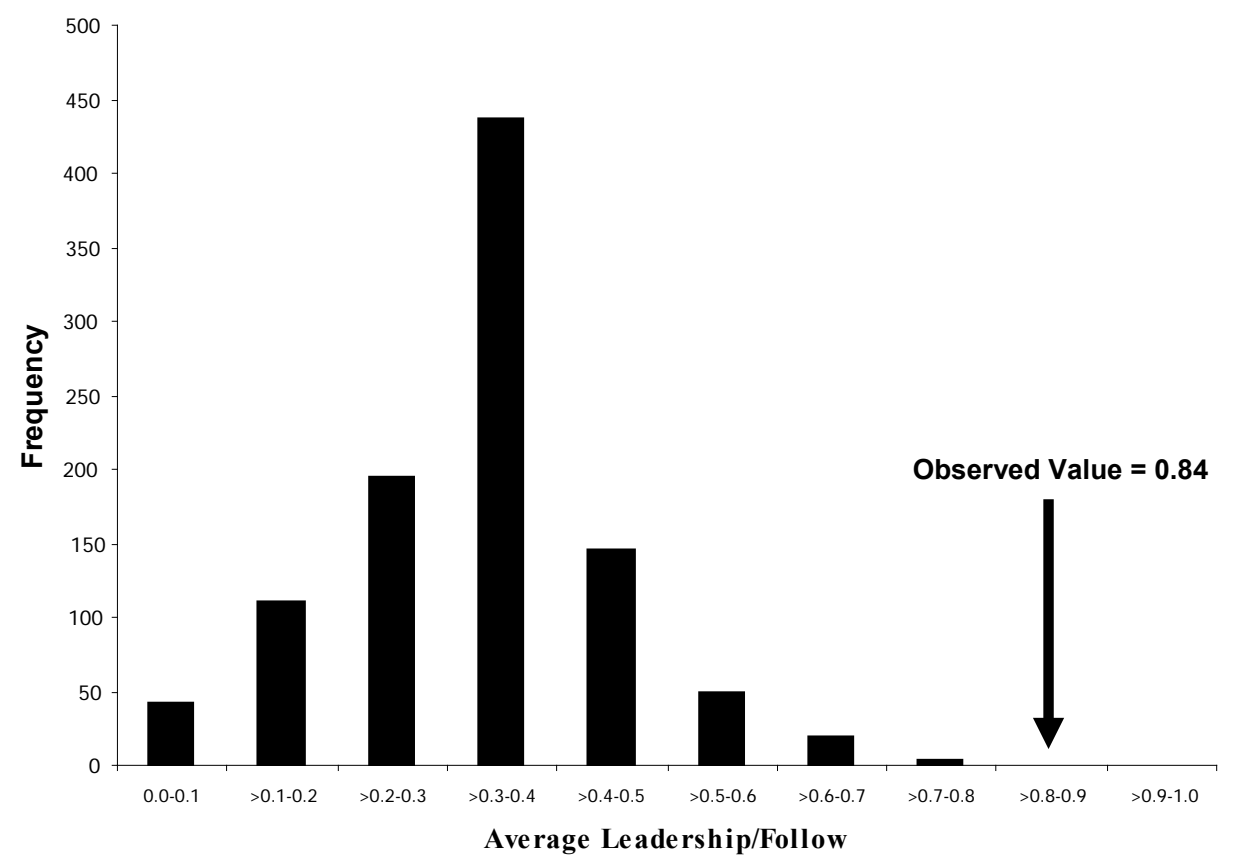

Figure 6. Example of a frequency histogram generated by randomizations $(\mathrm{n}=$ 1000 iterations) to test for greater than expected leadership by dolphin 057 . The observed value is indicated with an arrow. 


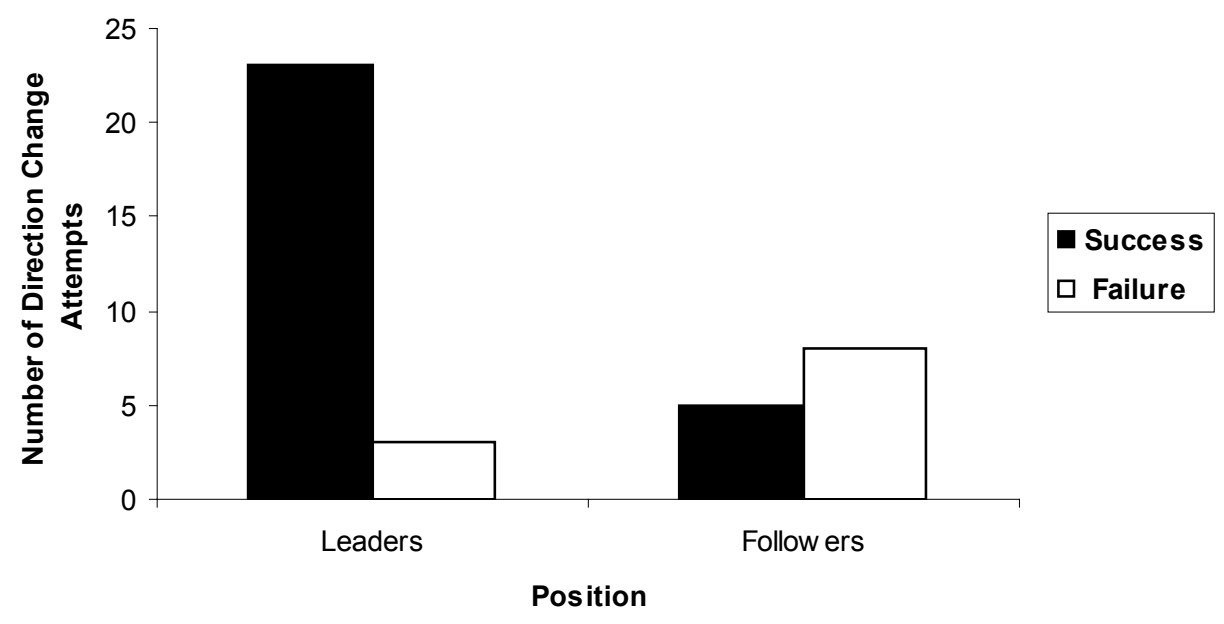

Figure 7. Number of successful and unsuccessful direction change attempts by leading and following bottlenose dolphins. 
CHAPTER III: PREDICTORS OF LEADERSHIP IN FISSION-FUSION GROUPS OF BOTTLENOSE DOLPHIN (TURSIOPS TRUNCATUS) 


\begin{abstract}
Which individuals lead in animal groups varies considerably among species. Predicting factors have included gender, physiological state, experience and social rank. I examined if certain factors including gender, reproductive state (with or without calf), and position within the existing social network, could predict which individuals would lead in a highly dynamic fission-fusion species, the bottlenose dolphin (Tursiops truncatus). I found that leaders were female, they were not close relatives, and all of reproductive ages were mothers. Additionally, leaders had central positions within the social network, indicated by high betweenness and degree values. Females in dynamic fission-fusion societies may be more likely to lead than males because they are driven by greater needs to locate resources (when taking care of young). However, as many follower females were also mothers, this cannot be the major force behind predicting leadership. Position in the social network is likely most important. Central positions within the network for these females resulted from associations with individuals from two communities. These associations occur across multiple areas where these communities are found, resulting in different space use by female leaders. More varied space use may indicate greater area knowledge, which could be useful to those who choose to follow them.
\end{abstract}

Key words: betweenness, centrality, degree, dolphin, fission-fusion, gender, leadership, social network, Tursiops truncatus 


\section{INTRODUCTION}

In many species, specific individuals act as group leaders when travelling (e.g., Peterson et al. 2002; King et al. 2008), yet the type of individual that leads varies considerably among species. For some cases, physiological state may be important, because hungry individuals may be strongly motivated to search for food (e.g., Krause 1993; Fischhoff et al. 2007). In some species, social rank determines who will make leadership decisions (e.g., wolves: Peterson et al. 2002; mongooses: Holekamp et al. 2000). While under other circumstances, experience may play a role (e.g., Reebs 2000; Jakimchuk and Carruthers, 1983; Payne 2003). Gender of leaders also varies, and may be tied to social status within a group (dominant males: Kummer 1971; Milton 2000 and dominant females: Rasa 1987), or to physiological needs (e.g., lactating females, Fischhoff et al. 2007).

Leading by specific individuals when travelling is expected to occur in relatively stable groups (Fischhoff et al. 2007). But, it now appears that leadership also can occur in highly dynamic fission-fusion species (Chapter II) (highly dynamic meaning changing group membership frequently over periods of days or hours). When individuals can make choices regarding whether to follow or to move independently, as occurs in fission-fusion grouping, predictors about who might lead most often are more difficult to identify. Because of variation in ecological and individual conditions, leadership and factors associated with leadership behavior may also vary. If specific individuals lead more often than expected however, then we might expect consistent predictors of leadership.

To examine which factors predicted who leads in a fission-fusion society, I studied a residential population of bottlenose dolphins (Tursiops truncatus) in the Lower 
Florida Keys (LFK), where evidence for specific individuals leading has been demonstrated (Chapter II). This species is characterized by frequent change in group membership (daily and hourly) (Connor et al. 2000), (average LFK group size $=4.4$, SD $=3.3$, Lewis 2002). However, in the LFK, the population is small (approximately 200 animals catalogued since 1999, Lewis unpublished data), and residential, creating the opportunity for individuals to associate frequently. Potential predictors investigated included gender, reproductive state, kinship (between leaders) and centrality within the social network.

\section{METHODS}

Data were collected for this study in the Lower Florida Keys (LFK) (Figure 1). Evidence for leading by specific individuals had been found in this area, (leading defined as having control of direction of group movement through initiation of direction changes and by leading through front position, Chapter II). Previous tests for leadership involved twenty individuals. Of these, three were found to lead more often than expected based on chance alone (Chapter II). I used these twenty individuals (leaders and followers) and examined if specific factors predicted who would be more likely to lead in this population.

Gender, Kinship and Reproductive State

Samples for analysis of gender and kinship were collected through biopsy surveys in the LFK. Biopsies were collected using a recurve crossbow (Barnett ${ }^{\circledR}$ Wildcat III) with 
modified bolt tips (see Krützen 2002 for design of bolt tip) and were stored in 20\% DMSO until analysis.

To determine kinship between leaders, I examined both genomic and mitochondrial DNA. Details for extraction, amplification and sequencing can be found in Chapter V. Using data from 18 loci, I calculated relatedness for each pair of leaders (Queller and Goodnight 1989). All loci used passed tests for Hardy-Weinberg equilibrium, linkage, and absence of null alleles. I compared the average relatedness value for all possible leader pairs to that of the population sampled (including leaderleader pairs and leader-follower pairs) using a Monte Carlo randomization test (1000 permutations). I considered the average relatedness value for leader pairs to be significantly different from random if it was greater than $95 \%$ of all randomly generated averages. Mitochondrial haplotypes were compared among leaders for further investigation of relatedness.

Gender of all individuals sampled was determined using a multiplex reaction patterned after Rosel et al. 2003. The Polymerase Chain reaction (PCR) mixture consisted of $1 \mu 1$ of template, $0.3 \mu 1$ of each primer (ZFX forward and reverse, and SRY forward and reverse), $0.2 \mu 1$ dNTPs, $0.25 \mu 1 \mathrm{MgCl}_{2}, 2.0 \mu 1$ buffer, $0.05 \mu 1$ Taq polymerase, and $15.3 \mu 1$ $\mathrm{ddH}_{2} \mathrm{O}$ for a final volume of $20 \mu 1$. The PCR started with initial denaturization for 4 minutes at $94^{\circ} \mathrm{C}$. This was followed by 34 cycles of $45 \mathrm{sec}$ at $94^{\circ} \mathrm{C}, 45$ seconds at $60^{\circ} \mathrm{C}$ and 60 seconds at $72^{\circ} \mathrm{C}$. Final extension was performed for 10 seconds at $72^{\circ} \mathrm{C}$. Results were compared to controls for a known male and female using gel electrophoresis $(1.5 \%$ agarose). 
To determine if physiological state affected who led the group, I considered motherhood in female leaders and followers. Motherhood was determined by the presence of a calf (defined as being $<2 / 3$ the size of an adult), on multiple dates $(>5)$, surfacing next to the female in question.

\section{Social Network Placement}

To test whether placement within the LFK social network could predict leadership I examined centrality measures. Data for this analysis were collected from transect surveys covering areas within the LFK study area between 1999 and 2007 (Figure 1). When dolphins were encountered I recorded location using a Global Positioning System, (GPS) (Garmin ${ }^{\circledR} 48$ ). Photographs were taken of all group members for identification (Würsig and Würsig 1977). Groups were defined as all individuals likely interacting who were within approximately $200 \mathrm{~m}$ of one another (i.e., traveling, foraging and socializing together). Photographic data were used to determine association indexes (using the Half Weight Index) for all pairs of individuals using SOCPROG (Whitehead 2008). Individuals used in this analysis had been sighted on at least 5 dates. To determine if associations were significantly different from random, I compared the CV calculated from my data to the distribution resulting from 20,000 permutations of the entire data set using SOCPROG (Bejder et al.1998; Whitehead 1997). The observed matrix was considered significantly different from random if the calculated CV was $>97.5 \%$ of the CV's for the created matrices. Additional testing for non-random associations (as suggested by Whitehead 2008), included comparison of the correlation value from 
random generated AI's to observed AI's and also testing if $\mathrm{S}^{2} \mathrm{x} H>5(\mathrm{~S}=$ social differentiation, $\mathrm{H}=$ mean number of associations per individual). Association index values were used to determine centrality of individuals within the LFK network. Centrality measures used included Betweenness (B) and Degree (D). Betweenness is the sum of the shortest paths between individuals in a network that pass through the individual investigated (Croft et al. 2008). Degree is the number of different associates an individual has. These measures were calculated using UCINET 6.0 (Borgatti et al. 2002). I tested if average centrality measures (B and D) were greater for leaders than expected using Monte Carlo randomizations tests where the average values for leaders were compared to the distribution of expected averages generated from the whole population of values (1000 permutations). I considered the average for leaders to be significantly different from random if it was greater than $95 \%$ of all randomly generated averages. For this analysis, I excluded one outlier follower (animal 85), who had a betweenness value $76.2 \%$ larger than any other follower (Table 1).

\section{RESULTS}

\section{Gender, Kinship and Reproductive State}

All leaders were female (Table 1). Ten followers were female (one determined by presence of calf, nine through genetics) and six were male, one follower was not biopsied and is of unknown gender. Leaders were not more closely related to one another than expected based on chance $(\mathrm{p}=0.10)$. Two leaders (animals 20 and 57) shared haplotypes. 
Two of the leaders were mothers (animals 20 and 57). Animal 107 (the third leader) has never been noted with a calf. Seven of the ten female followers were also mothers (Table 1).

\section{Social Network Placement}

When comparing associations calculated from the data to those predicted (through randomizations), I found the observed $\mathrm{CV}(\mathrm{CV}=0.77, \mathrm{SD}=0.16)$ was $>95 \%(\mathrm{p}>0.99)$ of the CV's randomly generated. Further support for non-random associations within the social network included an $\mathrm{r}$ value of 0.48 and $\mathrm{S}^{2} \mathrm{x} \mathrm{H}>5\left(1.06^{2} \times 50.1=55.2\right)$. Average betweenness values for leaders $($ mean $=69.6, \mathrm{SD}=42.4)$ were larger than those of followers $($ mean $=18.5, \mathrm{SD}=9.7)$ and greater than expected on the basis of chance $(\mathrm{p}=$ 0.02) (Figure 7a). Average degree values for leaders $($ mean $=43.3, \mathrm{SD}=2.3)$ were also larger than those for followers $($ mean $=37.1, \mathrm{SD}=6.2)$ and more than expected on the basis of chance $(p=0.03)$ (Figure $7 b)$.

\section{DISCUSSION}

This study provided details about factors that predict which animals lead within a highly dynamic fission-fusion society. Dolphin leaders in the LFK could be described by gender and reproductive state, however, they only differed from all followers in measure of centrality within the social network. Kinship with other leaders was not a useful predictor of leading. 
All leaders were female and most were mothers. Leading by females when traveling has been found in other social species with stable group composition (e.g., canids: Peterson et al. 2002; herpestids: Holekamp et al. 2000; ungulates: Reinhardt 1983; and some primates: Barelli et al. 2008). Female leadership has also been linked to additional resource requirements during pregnancy or lactation (e.g., Fischhoff et al. 2007). Anecdotal accounts of females leading when travelling have been noted in one other fission-fusion species, the African elephant (Loxodonta sp.) (Payne 2003). In the African elephant, female leaders are matriarchs (Payne 2003) (matriarchal groups are headed by the oldest female relative). Leadership in LFK bottlenose dolphin groups is not matriarchal (Chapter V) and results from the current study indicate leaders were not close kin. Whereas leaders are more closely related to those that follow them than expected based on chance (Chapter V) these relationships were not maternally linked (mitochondrial haplotypes differed). While most leaders documented in my study were mothers (and had been for the duration of time identified), almost all female followers were also mothers. Therefore, although it is possible that hunger may be driving who leads, it cannot be the only factor, because if it were, all females with calves should be found to lead on a more equal basis.

Female leadership in other social species is often associated with rank in the society (e.g., Peterson et al. 2002, Holekamp et al. 2000). The role of dominance in social structure is nearly impossible to document in wild cetaceans because the primary method for observation is from the surface. Dominance hierarchies have been described between pool mates in captive situations (Samuels and Gifford 1997) but no evidence for this type 
of social structure has been found under natural conditions, where group composition changes frequently.

While I cannot determine if dominance plays a role in leadership for this population, I was able to investigate whether social connections were important through network analysis. On average LFK leaders had larger degree and betweenness values than followers. The variation in betweenness values is similar to Indian Ocean bottlenose dolphins (Tursiops aduncus), where individuals performing behaviors used to communicate start and stop of movement (considered leaders) also had the greatest betweenness values (Lusseau 2007). It was hypothesized that the high betweenness values for the New Zealand population, allowed these individuals to have greater knowledge about which areas had already been depleted of prey (Lusseau 2007). High betweenness values result from associating with individuals from multiple groups that do not associate with one another. Large betweenness can indicate that the position of an individual is central to the social network for the area, and connects multiple groups that compose the network. Two distinct communities exist in the LFK study area (Lewis unpublished data). Individuals in these are divided by a large expanse of impassible water $\left(\sim 3.7 \mathrm{~km}^{2}\right)$. The associations that leaders have with animals from both communities resulted in larger degree and betweenness values compared to followers. These associations resulted from movement by leaders through both areas (noted by examining location of sightings when associations occurred).

Previous work on LFK dolphins indicated that whereas leaders do not have larger home ranges than followers (Chapter IV), their ranges include more distinct areas (distinct defined as having limited entrance or exit points, and therefore separated from 
other areas) (Chapter IV). To use these distinct areas, individual dolphins must be familiar with how to get in them and out of them (using deeper channels that provide access). The more of these areas an individual knows how to access, the better off that individual would be as competition with others or inaccessibility of some areas may vary through a day, or between days. That leaders had these distinct areas within their home ranges indicated knowledge or familiarity with these areas. That they had more of them than followers, indicated familiarity with more areas on average. Larger betweenness values found in this study also indicated familiarity with additional areas for leaders, as the associations they had that were distinct from other associations in the network were with individuals found in different areas. Having familiarity with more areas, leaders can be valuable for direction of movement through the LFK habitat. Experience has been noted as a predictor for leadership in some species (Jakimchuk and Carruthers 1983; Reebs 2000). Those with greater knowledge about potential resources would be able to provide the most benefit to followers.

My findings indicate that a subset of females may be important to the well being of the LFK dolphin population through leadership and that the extent of area familiarity is an important part of why they are LFK leaders. Access to additional profitable habitat benefits followers when access to other areas is either not possible or not profitable at that time. Because area familiarity takes time to acquire, loss of these individuals without the chance for others to also acquire that knowledge could negatively affect individuals in the population (Sih and Waters 2005, "keystone individual"). Therefore, it may be important to identify leaders in fission-fusion societies. Measures of social network 
centrality provide a tool to access information about potentially important individuals within those societies. 


\section{ACKNOWLEDGMENTS}

This project was supported through funding from the Harbor Branch Oceanographic Institute Protect Wild Dolphins Grant, Project Aware, and Sigma Xi. J. Lewis was supported in part the Dissertation Acquisition Fellowship and the Dissertation Year Fellowship from Florida International University. In kind support was provided by the Florida Keys National Marine Sanctuary (NOAA, Key West, FL), Key West Marina, NMFS Virginia Key, FL and NMFS Pascagoula, MS, and many volunteer interns. Laboratory space, equipment and training for genetic analysis of samples were provided by the Evolutionary Genetic Group at the University of Zürich, Switzerland (special thanks to Corinne Ackermann and Anna Koops). Data for this project were collected under NMFS Permit No. 779-1633, NMFS LOC No. 572-1639 and FIU IACUC No. 07003. 


\section{REFERENCES}

Barelli, C., Boesch, C., Heistermann, M., \& Reichard, U. H. (2008). Female whitehanded gibbons (Hylobates lar) lead group movements and have priority of access to food resources. Behaviour, 145(12), 965.

Bejder, L., Fletcher, D., \& Bräger, S. (1998). A method for testing association patterns of social animals Animal Behaviour, 56(3), 719-725.

Borgatti, S. P., Everett, M. G., \& Freeman, L. C. (2002). UCINET for windows: Software for social network analysis. Harvard, MA: Analytic Technologies,

Connor, R., Wells, R., Mann, J., \& Read, A. (2000). The bottlenose dolphin: Social relationships in a fission-fusion society. Cetacean Societies: Field Studies of Dolphins and Whales, pp. 91-126.

Croft, D. P., R. James and J. Krause. 2008. Exploring Animal Social Networks. Princeton University Press, Princeton, NJ.

Fischhoff, I. R., Sundaresan, S. R., Cordingley, J., Larkin, H. M., Sellier, M. J., \& Rubenstein, D. I. (2007). Social relationships and reproductive state influence leadership roles in movements of plains zebra, Equus burchellii. Animal Behaviour, 73(5), 825-831.

Holekamp, K. E., Boydston, E. E., \& Smale, L. (2000). Group travel in social carnivores. On the Move: How and Why Animals Travel in Groups, pp 587-627.

Jakimchuk, R. D., \& and Carruthers, D. R. (1983). Caribou on Victoria Island, Northwest Territories, Canada. Acta Zoologica Fennica, 175, 149-151.

King, A. J., Douglas, C., Huchard, E., Isaac, N. J. B., \& Cowlishaw, G. (2008). Dominance and affiliation mediate despotism in a social primate. Current Biology, 18(23), 1833-1838.

Krause, J. (1993). The relationship between foraging and shoal position in a mixed shoal of roach (Rutilus rutilus) and chub (Leuciscus cephalus): A field study. Oecologia, 93(3), 356-359.

Krützen, M., Barré, L. M., Möller, L. M., Heithaus, M. R., Simms, C., \& Sherwin, W. B. (2002). A biopsy system for small cetaceans: Darting success and wound healing in Tursiops spp. Marine Mammal Science, 18(4), 863-878.

Kummer, H. (1971). Primate societies Aldine-Atherton Chicago. 
Lusseau, D. (2007). Evidence for social role in a dolphin social network. Evolutionary Ecology, 21(3), 357-366.

Milton, K. (2000). Quo vadis? tactics of food search and group movement in primates and other animals. On the Move: How and Why Animals Travel in Groups, pp 375417.

Payne, K. (2003). Sources of social complexity in the three elephant species. Animal Social Complexity: Intelligence, Culture, and Individualized Societies, pp 57-85.

Peterson, R. O., Jacobs, A. K., Drummer, T. D., Mech, L. D., \& Smith, D. W. (2002). Leadership behavior in relation to dominance and reproductive status in gray wolves, Canis lupus. Canadian Journal of Zoology, 80(8), 1405-1412.

Queller, D. C., \& Goodnight, K. F. (1989). Estimating relatedness using genetic markers. Evolution, 43(2), 258-275.

Rasa, O. A. E. (1987). The dwarf mongoose: A study of behavior and social structure in relation to ecology in a small, social carnivore. Advances in the Study of Behavior, 17, 121-163.

Reebs, S. G. (2000). Can a minority of informed leaders determine the foraging movements of a fish shoal? Animal Behaviour, 59(2), 403-409.

Reinhardt, V. (1983). Movement orders and leadership in a semi-wild cattle herd. Behaviour, 251-264.

Rosel PE (2003) PCR-based sex determination in Odontocete cetaceans. Conservation. Genetics, 4, 647-649.

Samuels, A., \& Gifford, T. (1997). A quantitative assessment of dominance relations among bottlenose dolphins. Marine Mammal Science, 13(1), 70-99.

Sih, A., \& Watters, J. V. (2005). The mix matters: Behavioural types and group dynamics in water striders. Behaviour, 142, 9(10), 1417-1431.

Whitehead, H. (1997). Analysing animal social structure. Animal Behaviour, 53(5), 10531067.

Whitehead, H. (2008). Analyzing animal societies: Quantitative methods for vertebrate social analysis University Of Chicago Press.

Würsig, B., \& Würsig, M. (1977). The photographic determination of group size, composition, and stability of coastal porpoises (Tursiops truncatus). Science, 198(4318), 755-756. 
Table 1. Predictors of leadership examined for dolphins in the Lower Florida Keys. Columns header abbreviations stand for the following: ID = animal identity code, $\mathrm{P}=$ usual position ( $\mathrm{L}=$ Leader, $\mathrm{F}=$ Follower), $\mathrm{G}=$ gender $(\mathrm{F}=$ female, $\mathrm{M}=$ male, $\mathrm{U}=$ Unknown), $\mathrm{R}=$ reproductive status $(\mathrm{M}=$ mother, $\mathrm{NM}=$ not a mother, $\mathrm{na}=$ not applicable), $\mathrm{H}=$ haplotype (letters represent haplotypes, dashes indicate no sample taken for analysis), $\mathrm{B}=$ betweenness value, $\mathrm{D}=$ degree value. The symbol (*) indicates the follower who was considered an outlier and not included in tests for betweenness or degree. The symbol ( $)$ reflects a likely haplotype (but not tested). It was the haplotype for the calf of individual ID number 2 .

\begin{tabular}{|c|c|c|c|c|c|c|}
\hline ID & $\mathbf{P}$ & G & $\mathbf{R}$ & H & B & D \\
\hline 20 & $\mathrm{~L}$ & $\mathrm{~F}$ & $\mathrm{M}$ & A & 113.12 & 46 \\
\hline 57 & $\mathrm{~L}$ & $\mathrm{~F}$ & $\mathrm{M}$ & A & 67.35 & 42 \\
\hline 107 & $\mathrm{~L}$ & $\mathrm{~F}$ & NM & $\mathrm{D}$ & 28.348 & 42 \\
\hline 2 & $\mathrm{~F}$ & $\mathrm{~F}$ & $\mathrm{M}$ & $\mathrm{C}^{\wedge}$ & 36.228 & 46 \\
\hline $85^{*}$ & $\mathrm{~F}$ & $\mathrm{~F}$ & $\mathrm{M}$ & - & 151.69 & 47 \\
\hline 8 & $\mathrm{~F}$ & $\mathrm{~F}$ & $\mathrm{M}$ & $\mathrm{C}$ & 36.22 & 46 \\
\hline 21 & $\mathrm{~F}$ & $\mathrm{~F}$ & $\mathrm{M}$ & - & 7.416 & 34 \\
\hline 81 & $\mathrm{~F}$ & $\mathrm{~F}$ & $\mathrm{M}$ & - & 23.35 & 41 \\
\hline 83 & $\mathrm{~F}$ & $\mathrm{~F}$ & $\mathrm{M}$ & $\mathrm{C}$ & 17.21 & 40 \\
\hline 97 & $\mathrm{~F}$ & $\mathrm{~F}$ & $\mathrm{M}$ & - & 9.67 & 31 \\
\hline 116 & $\mathrm{~F}$ & $\mathrm{~F}$ & $\mathrm{NM}$ & $\mathrm{B}$ & 6.708 & 32 \\
\hline 98 & $\mathrm{~F}$ & $\mathrm{~F}$ & $\mathrm{NM}$ & - & 20.013 & 40 \\
\hline 101 & $\mathrm{~F}$ & $\mathrm{~F}$ & NM & - & 17.453 & 37 \\
\hline 115 & $\mathrm{~F}$ & $\mathrm{U}$ & $\mathrm{NM}$ & - & 24.42 & 34 \\
\hline 1 & $\mathrm{~F}$ & $\mathrm{M}$ & na & $\mathrm{C}$ & 19.51 & 41 \\
\hline 3 & $\mathrm{~F}$ & $\mathrm{M}$ & na & $\mathrm{E}$ & 22.27 & 40 \\
\hline 4 & $\mathrm{~F}$ & $\mathrm{M}$ & na & $\mathrm{C}$ & 22.22 & 41 \\
\hline 15 & $\mathrm{~F}$ & $\mathrm{M}$ & na & - & 22.69 & 40 \\
\hline 126 & $\mathrm{~F}$ & $\mathrm{M}$ & na & $\mathrm{F}$ & 8.023 & 29 \\
\hline 165 & $\mathrm{~F}$ & $\mathrm{M}$ & na & $\mathrm{D}$ & 3.182 & 23 \\
\hline
\end{tabular}



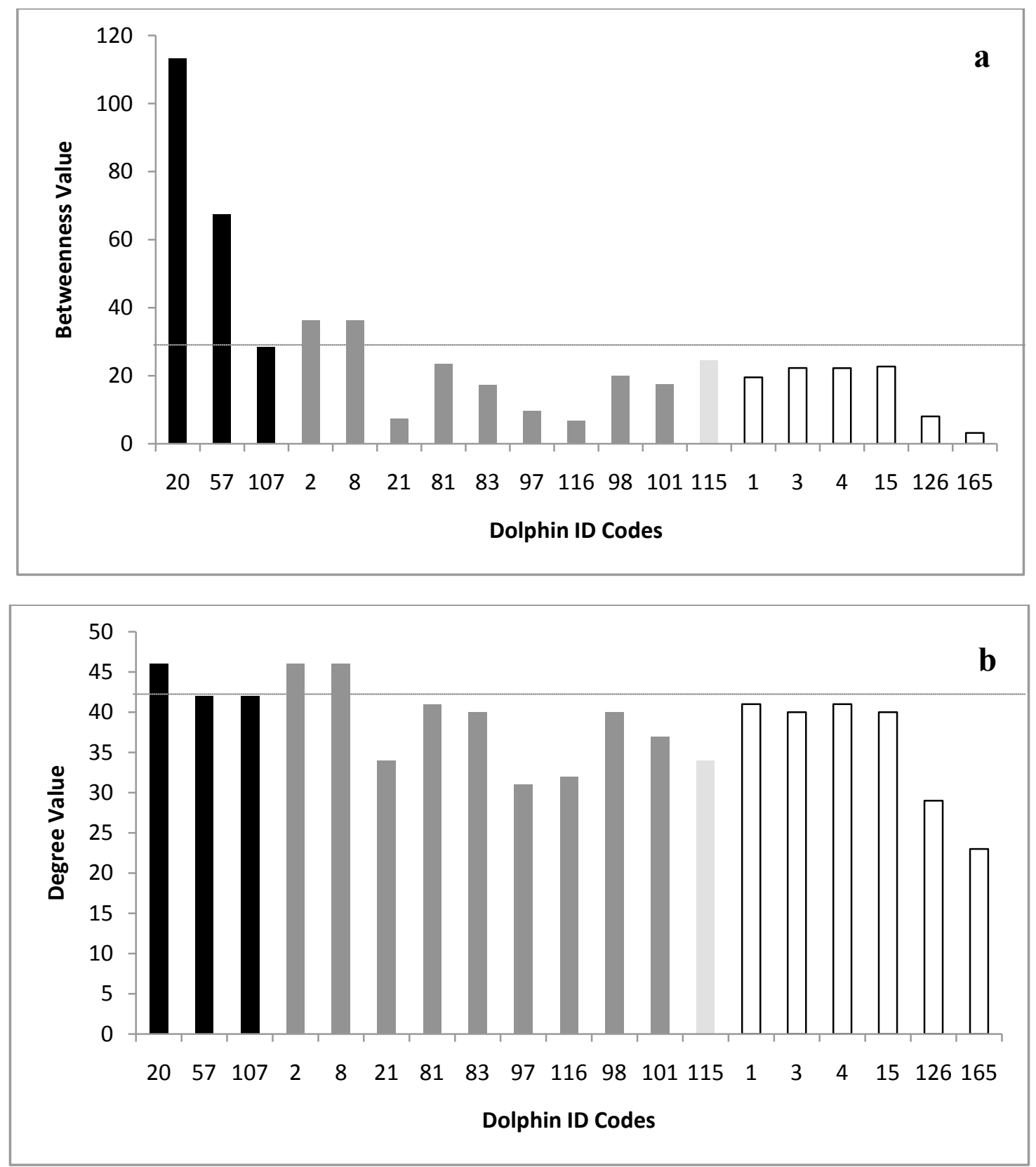

Figure 8. Measures of centrality for leaders and followers in dolphin groups in the Lower Florida Keys, (LFK) FL. (a) Betweenness values for dolphins in the LFK. (b) Degree values for LFK dolphins. Leaders are represented by black bars, followers include all other bars and are divided according to gender (dark gray $=$ female, light grey $=$ unknown and white $=$ male). All leaders are female. Lines indicate the level for the lowest measure for leaders. 
CHAPTER IV: LEADERSHIP PROVIDES BENEFITS TO FOLLOWERS IN FISSION-FUSION GROUPS 


\begin{abstract}
In dynamic fission-fusion societies, following specific individuals consistently would not be expected in the absence of benefits to followers. Followers in groups may benefit if leaders have greater knowledge about habitats that are available and can move more efficiently when traveling than most other individuals. A small residential population of bottlenose dolphins (Tursiops truncatus) in the Lower Florida Keys (LFK) demonstrates such specific individual leadership, but how it benefits followers remains unknown. To determine how followers might benefit from consistently following the same leaders, I 1) examined habitat use patterns for leader-led groups and follower-led foraging groups across areas that varied in resource profitability, (using relative prey biomass as a measure of habitat quality), 2) compared home range size and number of distinct areas (areas divided by islands or shallows) within home ranges between leaders and followers, and 3) compared directness of travel along with number of lead animal switches for leader-led and follower-led groups when traveling. Leader-led foraging groups did a better job at matching habitat profitability than follower-led groups, with increased predictability of sighting over habitat with higher prey availability, while follower-led groups had largest sighting predictability over habitat with lower prey availability. Foraging groups led by followers were smaller in size and had longer foraging bout lengths when compared to leader-led groups. Leader home ranges did not differ in size from those of followers, but contained more distinct areas. Leader-led groups made fewer lead animal switches and took more direct paths when traveling than follower-led groups. My results indicate that followers in LFK dolphin groups benefit from leader knowledge
\end{abstract}


of habitat profitability, ability to navigate efficiently and potentially the number of areas leaders are familiar with.

Key words: dolphin, directness of travel, fission-fusion, follower benefits, habitat matching, leadership, travel 


\section{INTRODUCTION}

Many benefits have been ascribed to group formation in animal societies including increased probability of locating resources (Krause and Ruxton 2002). The presence of such benefits may help explain why animals, given the choice, will follow specific individuals on a regular basis. In fission-fusion species, group members can choose to join or leave groups, and likely make these decisions based on an individual cost-benefit analysis (e.g., Wittemyer et al. 2005; Lehmann et al. 2007; Smith et al. 2008). Under conditions in which interaction with the same individuals can occur regularly, individuals may learn that benefits can be gained from following specific individuals and these benefits may be greater than when leading themselves, creating the impetus for consistent leading by a subset of the population.

Benefits may be provided to followers if leaders are more knowledgeable about the environment where they live. This knowledge source may include where and how to locate resources. Area knowledge may come from the experience of a leader, providing a resource for more naïve followers. Controlled tests have shown that naïve individuals tend to follow experienced individuals when searching for food (Reebs 2000). Similar reports have been made in the field. For example, accounts of traveling gorillas have described group members looking to older experienced males for leadership when moving across a new or complex environment (Byrne 2000). In African elephants, older individuals (matriarchs) have been documented to provide leadership by locating distant resources learned many years before (Viljoen 1990; Payne 2003). 
Followers may benefit from leader regional knowledge by following leaders to profitable habitat for foraging, and through more efficient travel to these areas. Habitat quality (e.g., food availability) will vary spatially and leaders may provide benefits to followers by having greater knowledge about spatial and temporal variation in habitat quality and accessibility. In addition, leaders may also have knowledge about a greater number of areas in which to forage. Knowing how to navigate into and through more areas (and to navigate efficiently) could provide more opportunities for resource location if the additional areas contain quality habitat. This ability could be important if resources become depleted in well-known areas. Access to more potential foraging areas may also be important to avoid intraspecific competition (e.g., Boydston et al. 2003; Kahl and Radke 2005). Efficient navigation would decrease energy waste when groups move from one foraging location to another (e.g., Poctran 2005; Noser and Byrne 2007).

To test if followers receive benefits from leadership, I examined a fission-fusion population of bottlenose dolphins (Tursiops truncatus) in the Lower Florida Keys (LFK) where leadership by specific individuals when traveling has been documented (Chapter II). To determine if leaders provided benefits through use of more profitable habitat, I examined 1) the predictability of locating leader-led and follower-led groups in areas that varied in resource profitability (relative prey biomass), 2) whether group size varied across these conditions (group type and habitat type), and 3) the time spent foraging in these groups. If leaders have greater understanding about resource profitability per habitat, then I expected that leader-led groups would forage in higher profit habitat more often than lower profit habitat and the opposite would be noted for follower-led groups. I 
also expected that if followers benefited from leadership, that leader-led groups might be larger than follower-led groups, and that variation in group size may depend on the profitability of habitat type used at the time. Finally, I expected that if leaders provide foraging benefits, that time spent foraging might reflect this, with leader-led groups spending less time foraging because the chances for location of resources is greater.

In addition to knowledge of specific habitat profitability, leaders may also have more extensive habitat area knowledge. To test extent of habitat knowledge I compared home range characteristics between leaders and followers (area size and number of distinct regions within). The LFK is composed of multiple large shallow basin-like areas divided by islands and impassible shallows $(<0.3 \mathrm{~m})$. Limited entrance/exit points (channels) provide access to these. To utilize them effectively individuals must become familiar with how to (where) and when to (according to tides) access them. If home ranges for leaders are larger in size or have more distinct areas within them, this would indicate familiarity with more area. If this increase in area familiarity includes profitable habitat, followers could benefit because resources may vary daily (e.g., intraspecific competition or inaccessibility due to tidal changes).

Finally, to test if leaders provide more efficient travel, I examined directness of travel along with the frequency of lead animal switches when travelling, comparing leader-led groups to follower-led groups. If leaders are more familiar with the study area, then I expected them to move more efficiently through it. 


\section{METHODS}

\section{Habitat use when foraging}

The study area, the Lower Florida Keys (LFK) (Figure 1) is heterogeneous and complex, consisting of expanses of shallow (range $0.5-4.0 \mathrm{~m}$ ) vegetated areas (primarily sea grass and some algae) and shallow unvegetated areas (sand bottom), divided by deeper channels (range $>4-10 \mathrm{~m}$ ) and mangrove islands. Adding to this complexity, there are limited access points into and out of each larger basin, and tidal fluctuations affect the usability of various regions. Changes in water level affect the ability of dolphins to maneuver across the habitat (i.e., vast expanses of shallows are exposed during low tides, or are too shallow for dolphins to swim through). Because the LFK is composed of multiple benthic habitat types, and these may vary in profitability, benefits to followers may occur if leaders are more aware of these differences, and make use of that information.

To test whether leaders provide benefits to followers by using profitable habitat more often, I compared the predictability of sightings for foraging leader-led and follower-led groups across habitats that varied in prey availability. Leaders were defined as individuals that led group movement more often than expected via chance (through vanguard position and success at change in the groups direction), whereas followers did not (Chapter II). To determine patterns of habitat use, I examined one specific area, Man of War Harbor (MOW) (Figure 8). This area was chosen because 1) it was surveyed most frequently, so a sizable data set was available and 2) it contained equal portions of two 
benthic habitat types (shallow vegetated and deep channel), which varied in prey availability (see Results).

I examined dolphin habitat use within MOW using locations when groups were foraging (defined below). Dolphins were located using transect surveys running north and south through MOW, allowing me to examine the entire area on each survey day. When dolphin groups were located, I recorded location (latitude and longitude) using a Global Positioning System, GPS (Garmin $\left.{ }^{\circledR} 48\right)$. Groups were defined as all individuals within approximately 100 meters of one another who were likely interacting (i.e., traveled, foraged and socialized together) following Shane (1990).

After groups were located, behavior state (travel, foraging and socializing) and location were sampled at point intervals (every $5 \mathrm{~min}$ ). Travel was defined as continuous directional movement. Foraging was defined as variable surfacing (i.e., each surface in a different direction), with no direct contact with other group members and exhibiting other foraging indicative behaviors such as diving deeply, chasing fish, capturing fish, bottom digging (Rossbach and Hertzing 1997) or "mud plume feeding" (Lewis and Schroeder 2003). Social behavior was defined as vigorous activity, with foraging indicative behavior absent, and usually with contact between group members occurring. Leadership was ascertained through continuous sampling of animal identity (using variation in dorsal fins) and position when surfacing, and by success of direction change initiation (defined as a change in heading $>35^{\circ}$ ) (see Chapter II for further details about methods to determine leadership). Dorsal fins of all group members were photographed and individuals were later verified using photo-identification (Würsig and Würsig 1977). 
Habitat use was determined for the location during the first foraging record for each group sample using benthic habitat maps of the LFK (O’Keife 1998) in ArcGIS ${ }^{\circledR}$ 9.3.

I examined prey availability by fish sampling across habitat types available in the LFK study area (shallow vegetated, shallow unvegetated and deep channel). Within each benthic habitat, six sites were chosen randomly to sample. Sampling was done using fish traps constructed of $11 \mathrm{~mm}$ square wire mesh. I used two sized traps at each site. Large traps (Antillean Z traps, Sheaves 1992) (dimensions $=70 \mathrm{~cm}$ long, $55 \mathrm{~cm}$ high and $40 \mathrm{~cm}$ wide) and small bait traps (dimensions $=37 \mathrm{~cm}$ long, $33 \mathrm{~cm}$ high and $32 \mathrm{~cm}$ wide) were used to sample fishes of different size classes. Fish captured in each size trap were significantly different in size $(\mathrm{cm})$ (Friedman tests with Bonferoni correction; deep channel: $X^{2}=12$, df $=1, p<0.001$, shallow vegetated: $X^{2}=12, d f=1, p<0.001$, shallow unvegetated: $\left.X^{2}=6, d f=1, p=0.014\right)$. I sampled both size classes of fish because LFK dolphins had been seen consuming fish from each size class. The two traps (large and small) were spaced at a distance of approximately $80 \mathrm{~m}$ to insure that they were sampling the same habitat type but prevented trap attraction radii from overlapping (Heithaus and Dill 2002). Traps were baited with menhaden chum and set for approximately 2 hours to allow enough time for capture without loss of effectiveness (Sheaves 1995, Heithaus and Dill 2002). Fish captured were identified, weighed (g) (Ohaus ${ }^{\circledR}$ CS200), measured (fork length, cm) and counted. All captured fish were released.

Fish sampling sites were combined for each habitat type after determining there was no difference between them (Kruskal Wallis tests; shallow unvegetated bait traps: $\mathrm{X}^{2}$ $=0.98, \mathrm{df}=2, \mathrm{p}=0.612$, shallow unvegetated $\mathrm{Z}$ traps: $\mathrm{X}^{2}=0.58, \mathrm{df}=2, \mathrm{p}=0.747$, 
shallow vegetated bait traps: $X^{2}=4.69, d f=5, p=.454$, shallow vegetated $Z$ traps: $X^{2}=$ $6.25, \mathrm{df}=5, \mathrm{p}=.282$, deep channel bait traps: $\mathrm{X}^{2}=3.215 . \mathrm{df}=5, \mathrm{p}=0.667$, deep channel $\mathrm{Z}$ traps: $\left.\mathrm{X}^{2}=5.109, \mathrm{df}=5, \mathrm{p}=.403\right)$. Using sampling data, I calculated yield-perunit-effort (biomass $\mathrm{g} / \mathrm{hr}$ ) for each benthic habitat and then used this relative prey biomass measure to compare habitats for each trap type.

From data collected on dates where MOW was surveyed fully, I determined the type of group encountered (leader-led or follower-led), group size, and the habitat type where dolphins were located (deep channel or shallow vegetated). From each group sample, I determined the location of the first foraging bout. I used a logistic regression to test whether habitat type (shallow vegetated or deep channel), group type (leader-led or follower-led), or the interaction of these two predicted sightings of foraging groups in MOW. To determine whether group size was related to group type or habitat type for foraging groups in MOW, I used a General Linear Model after log transforming group size. Finally, I tested association between time spent in each foraging bout and the size of the group.

\section{Area use by leaders and followers}

To determine if leaders differed from followers in extent of area familiarity I examined home range size and number of distinct areas within home ranges for each. Location points used were collected from first sight data for individuals between 1999 and 2009. Home ranges contours (95\%) were calculated for each individual using fixed kernel estimators (least squares) (Worton 1989) with $\mathrm{ArcView}^{\circledR}$ 3.2, Animal Movement 
Extension (Hooge and Eichenlaub 1997). Bootstrap sampling was used to determine the number of samples required to reach an asymptote (for certainty of home range calculations). Area of home range $\left(\mathrm{km}^{2}\right)$ was calculated for each individual after outliers were removed, and after land was removed. Average home range size for leaders was compared to the frequency distribution of average home range sizes created by randomizing (1000 permutations) home ranges for all individuals (Monte Carlo test, Manly 2006).

For each individual, I then determined the number of distinct areas within the $95 \%$ contour. Areas were considered distinct if divided from other areas by islands or extreme shallows $(<0.3 \mathrm{~m})$ with a limited number of entrance/exit points. Having a distinct area within an individuals home range, indicated that the individual was familiar with that area. All distinct areas within home ranges of LFK animals contained habitat with high prey availability (shallow vegetated). Having familiarity with more distinct areas could be advantageous as one could use these when prey is depleted in other areas (e.g., resulting from competition) or when other areas are inaccessible during low tides (which affects each area similarly regardless of size). I tested whether leaders had more distinct areas within their home range contours than expected based on chance using a Monte Carlo randomization test (1000 permutations).

\section{Travel Efficiency}

To test whether leader-led groups were more efficient travelers than follower-led groups I examined directness of paths taken and the number of vanguard (i.e., front position) 
animal switches that occurred when traveling. All travel bouts used were made across waters navigable and not dangerous to traveling dolphins. Vanguard position has previously been found to be associated with the ability to successfully change group direction (Chapter II). Time of travel was determined using data from group sampling. Directness of travel was determined by calculating the distance between each location point (latitude and longitude) when traveling, adding these together, and then dividing the distance between the first point and the last point into this sum. Blocks in movement were considered for each travel path (e.g., islands) so that directness measured was accurate (i.e., how direct was the path considering movement had to deviate around the island). The ratio calculated provided a measure of how direct the selected path was. I compared path directness ratios between leader-led and follower-led groups using a Mann-Whitney test. To measure the number of vanguard animal switches during travel for leader-led and follower-led groups, I used the first 30 min of each group sampling when the group was traveling. I counted the number of switches in animals for vanguard position, and compared leader-led groups to follower-led groups using a Mann-Whitney test. I then examined if these two measures (path directness and number of lead animal switches) were associated using a Spearman Rank correlation. Data pairs used for this test were both collected from the same time period within the group sample. 


\section{RESULTS}

\section{Habitat use when foraging}

Prey biomass varied between benthic habitat types, with the greatest biomass in shallow vegetated habitat $($ mean $=95.1 \mathrm{~g} / \mathrm{hr}, \mathrm{SD}=95.5)$, followed by deep channel $($ mean $=76.6 \mathrm{~g} / \mathrm{hr}, \mathrm{SD}=121.0)$ and then shallow unvegetated areas $($ mean $=48.6 \mathrm{~g} / \mathrm{hr}$, $\mathrm{SD}=99.4)($ Kruskal Wallis: $\mathrm{H}=34.6, \mathrm{df}=2, \mathrm{p}<0.0001)$ (Figure 9).

The interaction of group type and habitat type predicted sightings of foraging groups in MOW $\left(\mathrm{X}^{2}=6.68, \mathrm{df}=1, \mathrm{p}=0.009\right)$ (Figure 10). Group type predicted group size $(\mathrm{t}=3.7, \mathrm{df}=1,46, \mathrm{p}<0.0001)$, and group sizes varied according to group type $(\mathrm{U}=$ $333, \mathrm{z}=-3.22, \mathrm{p}<0.001)$, with smaller group sizes in follower-led groups (mean $=2.6$, $\mathrm{SD}=2.4)$ compared to leader-led groups (mean $=5.9, \mathrm{SD}=3.9)$. Smaller groups had longer foraging bouts than larger groups $\left(n=41, r_{s}=-0.34, p=0.009\right)$ (Figure 11).

Area use by leaders and followers

Most dolphins tested individually (18 of 20) reached an asymptote in home range size at approximately 20 observations. The number of sightings for all individuals ranged from 32 to 109 . I was therefore confident that the kernel contours calculated were representative of the true home ranges. The average home range size for leaders (mean $=$ $\left.24 \mathrm{~km}^{2}, \mathrm{SD}=17.7\right)$ was larger than that for followers $\left(\right.$ mean $\left.=21 \mathrm{~km}^{2}, \mathrm{SD}=11.3\right)$, but not significantly larger than expected based on chance $(p=0.37)$. The average number of 
distinct areas within the $95 \%$ contour for leaders (mean $=5.6, \mathrm{SD}=0.57$ ) was larger than that for followers $($ mean $=3.5, \mathrm{SD}=0.61)(\mathrm{p}=0.001)($ Figure 12)

\section{Travel Efficiency}

Leader-led groups traveled in more direct paths $($ mean $=0.76, \mathrm{SD}=0.28)$ than followerled groups (mean $=0.69, \mathrm{SD}=0.27)(\mathrm{U}=351.5, \mathrm{z}=1.67, \mathrm{p}=0.04)$, and they made fewer vanguard animal switches when traveling (leader led: mean $=3.11, \mathrm{SD}=2.8$; follower led: mean $=4.86, \mathrm{SD}=3.3)(\mathrm{U}=606.5, \mathrm{z}=-1.97, \mathrm{p}=0.02)($ Figure 13). Travel paths taken by dolphin groups were more direct when the group had fewer vanguard animal switches $(\mathrm{n}=86, \mathrm{r}=-0.33, \mathrm{p}=0.0001)$ (Figure 14).

\section{DISCUSSION}

Results of my study indicate that in fission-fusion societies, choosing to follow instead of leading can be beneficial for some individuals. Followers in leader-led groups benefit because these group types distribute themselves to match habitat profitability and move more directly when traveling, potentially increasing movement efficiency. Leaders also offer familiarity with more total area, using more distinct areas than followers.

Across the area tested (MOW), leader-led groups were better than follower-led groups at distributing themselves according to the resource potential of habitats when foraging. For leader-led groups in MOW, sighting predictability was greater in areas with 
high relative prey availability (shallow vegetated), while follower-led groups were sighted most often over low prey habitat (deep channel). These results indicate that dolphins likely benefit from following leaders, as they are choosing to follow individuals who are more likely to forage over profitable habitat. In fact, all leader-led foraging groups, regardless of location, were larger than follower-led groups, indicating a preference for joining leader-led groups over follower-led groups. Leader-led foraging groups also had shorter foraging bouts. As leader-led foraging groups were sighted more often over profitable habitat (shallow vegetated), location of prey should be more frequent. Larger groups also provide more chances for prey encounter (Krause and Ruxton 2002). Increased chance of prey encounter (through location of foraging and increased group size) would benefit all individuals who are members of these groups.

In addition to knowledge about habitat profitability (indicated by the increased sighting frequency of leader-led groups over habitat with higher prey availability in MOW), leaders may also benefit followers if leaders have more expansive knowledge of the area. Whereas home range sizes did not differ between leaders and followers in the LFK, leader home ranges did contain more distinct areas than follower home ranges (each distinct area containing profitable habitat). As there are limited entrance/exit points into these areas a certain amount of learning is required to access them. That these areas were within the leaders home ranges indicates that leaders have familiarity with them. With additional area information, leaders can then lead into more areas available for LFK followers where resources may be accessed. How to (and when to) access additional areas would be beneficial if resources were currently not available in other areas, either 
through depletion, inaccessibility to individuals (because daily tidal changes occur) or because of intraspecific competition with other dolphins.

Evolutionary forces should drive group travel behavior patterns towards that which is beneficial to group members. Shared leadership occurs to greater and lesser degrees within groups for some species (e.g., alpha male and alpha female in wolf packs, Peterson et al. 2002). Conflicts however, should arise when too many individuals partake in decision making. Such conflicts can decrease if group members take turns leading (Harcourt et al. 2009). But, when traveling, it only takes a small number of individuals to get from point A to point B accurately (Couzin et al. 2005). It therefore follows that directness of travel should be enhanced when fewer individuals participate in leading, and that directness in travel should be desired when efficiency is of interest for group members (e.g., Noser and Byrne 2007; Williams et al. 2009). My results indicated that leader-led groups moved in more efficient (straighter) paths (when traveling) compared to follower-led groups, and that this may be achieved by making fewer changes in leadership during travel. If leaders have greater knowledge about the location of resources, they will be more likely to move towards these resources in a more direct manner (Poctran 2005; Noser and Byrne 2007).

Certain criteria may be necessary for individuals in fission-fusion societies to determine that there is something to be gained from following specific individuals more often than leading themselves. Habitat complexity may provide the motivation for this behavior choice. The LFK marine environment is complex, with multiple benthic habitats and regions divided by large expanses of impassible area. Additionally, this region is 
shallow (average depth $\sim 1 \mathrm{~m}$ ), affecting locations where fish can be accessed with daily fluctuations in tides. Daily changes in ability for dolphins to maneuver (as tides fluctuate), mean that a certain level of knowledge about this area is important for success and survival. Following those who have more experience would then be more likely to occur.

Following individuals with more experience or greater specific area knowledge may be important to the short and long term well being of the LFK dolphin population. If leaders provide greater foraging opportunities, or waste less energy when travelling to foraging sites, individuals that follow them should do better than when searching on their own. Sudden loss of these leaders could then be detrimental to the health of the LFK population. 


\section{ACKNOWLEDGMENTS}

Financial support for this project was provided by Harbor Branch Oceanographic Institute Protect Wild Dolphins Grant, Project Aware and Sigma Xi. J. Lewis was supported during data analysis and write up by the Dissertation Acquisition Fellowship and Dissertation Year Fellowship from Florida International University. In kind support was provided by the Florida Keys National Marine Sanctuary (Key West, FL) and Key West Marina. A special thanks to all volunteers who assisted with field efforts. Data for this project were collected under NMFS GA LOC No. 572-1639, FFWCC SAL No. 07SR-1020C and Florida International University IACUC No. 03-020 and 07-003. 


\section{REFERENCES}

Boydston, E. E., K. M. Kapheim, M. Szykman, and K. E. Holekamp. 2003. Individual variation in space use by female spotted hyenas. Journal Information 84, (3).

Byrne, R. W. 2000. How monkeys find their way: Leadership, coordination, and cognitive maps of African baboons. In On the Move., ed. S. Boinski and P. A. Garber, 491. Chicago: University of Chicago Press.

Couzin, I. D., J. Krause, N. R. Franks, and S. A. Levin. 2005. Effective leadership and decision-making in animal groups on the move. Nature 433, : 513-6.

Deneubourg, J. L., S. Aron, S. Goss, and JM Pasteels. 1990. The self-organizing exploratory pattern of the argentine ant. Journal of Insect Behavior 3, (2): 159-68.

Harcourt, J. L. 2009. Social feedback and the emergence of leaders and followers. Current Biology 19, (3) (-02-10): 248-52.

Heithaus, M. R., and L. M. Dill. 2002a. Food availability and tiger shark predation risk influence bottlenose dolphin habitat use. Ecology 83, (2): 480-91.

Hooge, P. N., and B. Eichenlaub. 1997. Animal Movement extension to ArcView. version 1.1. Anchorage, AK: Alaska Biological Science Center, U. S. Geological Survey.

Kahl, U., and RJ Radke. 2005. Habitat and food resource use of perch and roach in a deep mesotrophic reservoir: Enough space to avoid competition? Ecology of Freshwater Fish 15, (1): 48-56.

Krause, J., and G. D. Ruxton. 2002. Living in groups. Oxford University Press, USA.

Lehmann, J., A. H. Korstjens and R. I. M. Dunbar. 2007. Fission-fusion social systems as a strategy for coping with ecological constraints: a primate case. Evolutionary Ecology 21: 613-634.

Lewis, J., and WW Schroeder. 2003. Mud plume feeding, a unique foraging behavior of the bottlenose dolphin (Tursiops truncatus) in the Florida keys. Gulf Mex.Sci 1, : 9297.

Manly, B. F. J. 2006. Randomization, bootstrap and Monte Carlo methods in biology Chapman \& Hall/CRC.

Noser, R., and R. W. Byrne. 2007. Travel routes and planning of visits to out-of-sight resources in wild chacma baboons, Papio ursinus. Animal Behaviour 73, (2): 257-66. 
O'Keife, K. 1998. Benthic habitats of the Florida keys. Florida Marine Research Institute technical report, TR-4. : 54 pp.

Payne, K. 2003. Sources of social complexity in the three elephant species. Animal Social Complexity: Intelligence, Culture, and Individualized Societies: 57-85.

Peterson, R. O., A. K. Jacobs, T. D. Drummer, L. D. Mech, and D. W. Smith. 2002. Leadership behavior in relation to dominance and reproductive status in gray wolves, Canis lupus. Canadian Journal of Zoology 80, (8): 1405-12.

Pochron, S. T. 2005. Does relative economic value of food elicit purposeful encounter in the yellow baboons (Papio hamadryas cynocephalus) of Ruaha National Park, Tanzania? Primates 46, (1): 71-4.

Reebs, S. G. 2000. Can a minority of informed leaders determine the foraging movements of a fish shoal? Animal Behaviour 59, (2): 403-9.

Rossbach, K. A., and D. L. Herzing. 1997. Underwater observations of benthic-feeding bottlenose dolphins (Tursiops truncatus) near Grand Bahama Island, Bahamas. Marine Mammal Science 13, (3): 498-504.

Shane, SH. 1990. Behavior and ecology of the bottlenose dolphin at Sanibel island, Florida. The Bottlenose Dolphin: 245-65.

Sheaves, M. J. 1992. Patterns of distribution and abundance of fishes in different habitats of a mangrove-lined tropical estuary, as determined by fish trapping. Aust J Mar Freshwat Rcs 43, (6): 1461-79.

Sheaves, M. J. 1995. Effect of design modifications and soak time variations on antilleanZ fish trap performance in a tropical estuary. Bulletin of Marine Science 56, (2): 47589.

Smith, J. E., J. M. Kolowski, K. E. Graham, S. E., Dawes and K. E. Holekamp. 2008. Social and ecological determinants of fission-fusion dynamics in the spotted hyena. Animal Behaviour 76: 619-636.

Viljoen, P. J. 1990. Daily movements of desert dwelling elephants in the northern Namib Desert. South African Wildlife Research 20(2), 69-72.

Williams, R., D. E. Bain, J. C. Smith, and D. Lusseau. 2009. Effects of vessels on behaviour patterns of individual southern resident killer whales Orcinus orca. Endang Species Res 6: 199-209. 
Wittemyer, G., I. Douglas-Hamilton and W. M. Getz. 2005. The socioecology of elephants: an analysis of the processes creating multitiered social structures. Animal Behaviour 69: 1357-1371.

Worton, B. J. 1989. Kernel methods for estimating the utilization distribution in homerange studies. Ecology 70, : 164-168.

Würsig, B., and M. Würsig. 1977. The photographic determination of group size, composition, and stability of coastal porpoises (Tursiops truncatus). Science 198, (4318): 755-6. 


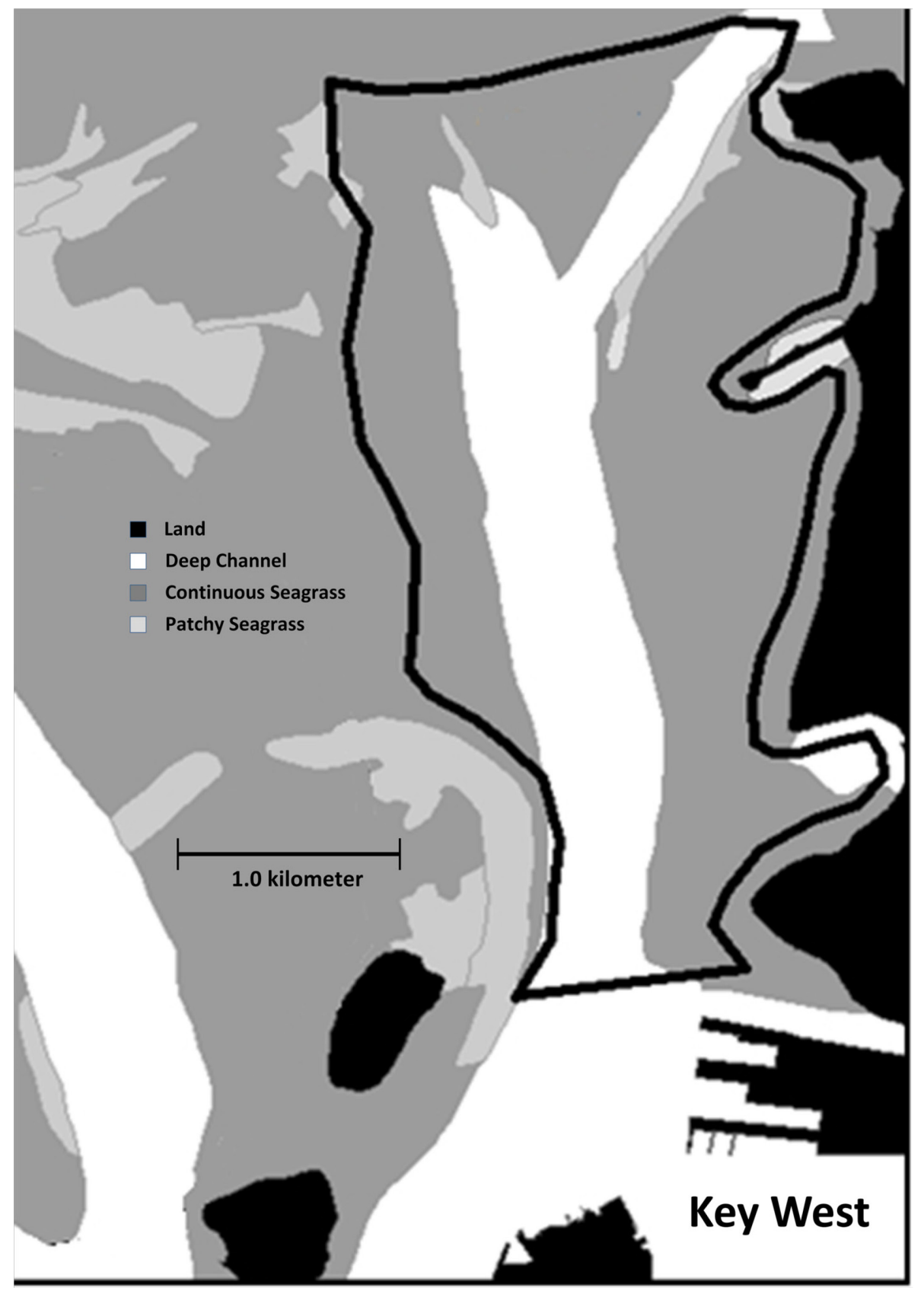

Figure 9. Map of benthic habitats in Man of War Harbor (circled in black). 


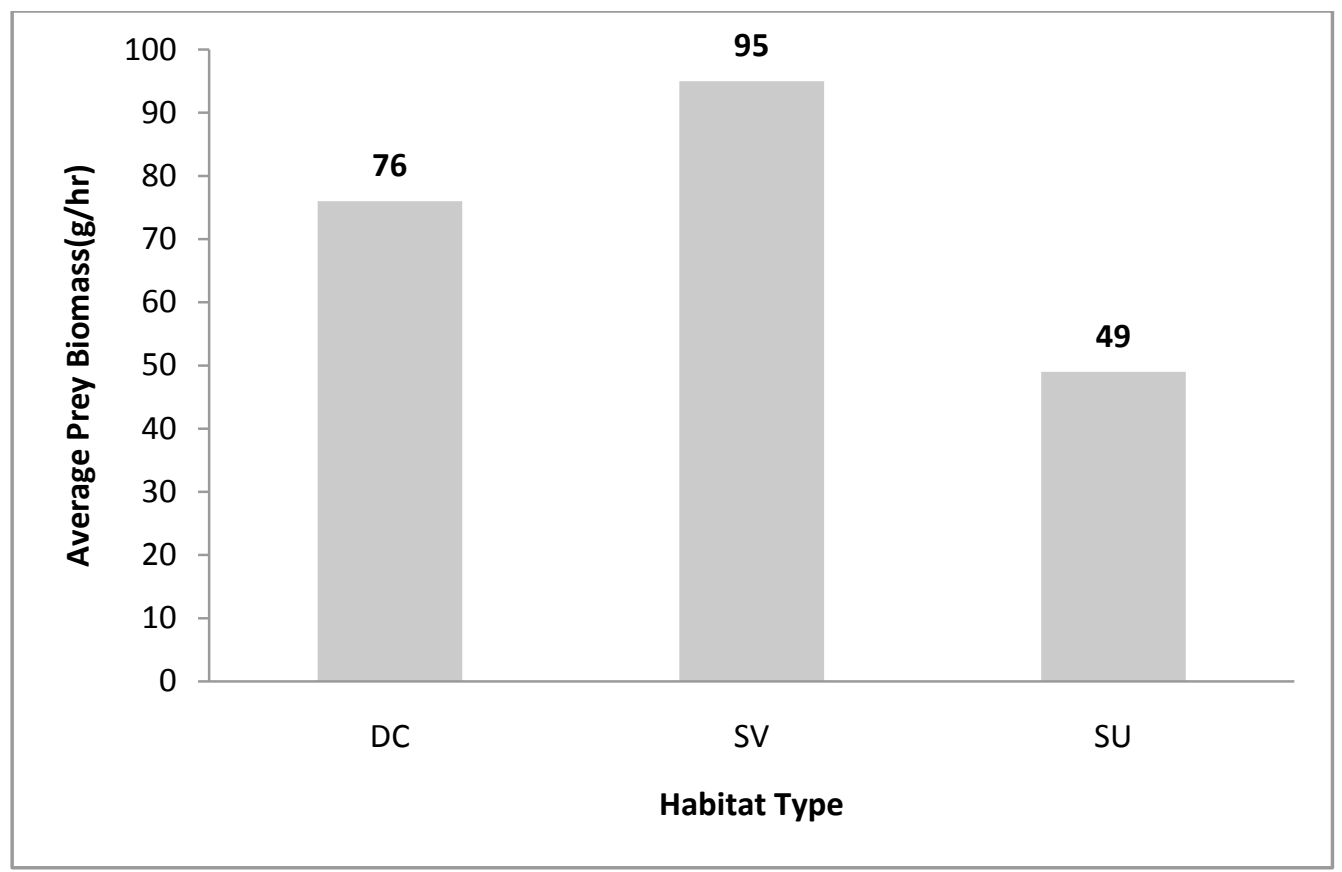

Figure 10. Relative biomass of fish available to dolphins in the Lower Florida Keys in three available habitats, (SU $=$ Shallow Unvegetated, SV $=$ Shallow Vegetated and DC = Deep Channel). 


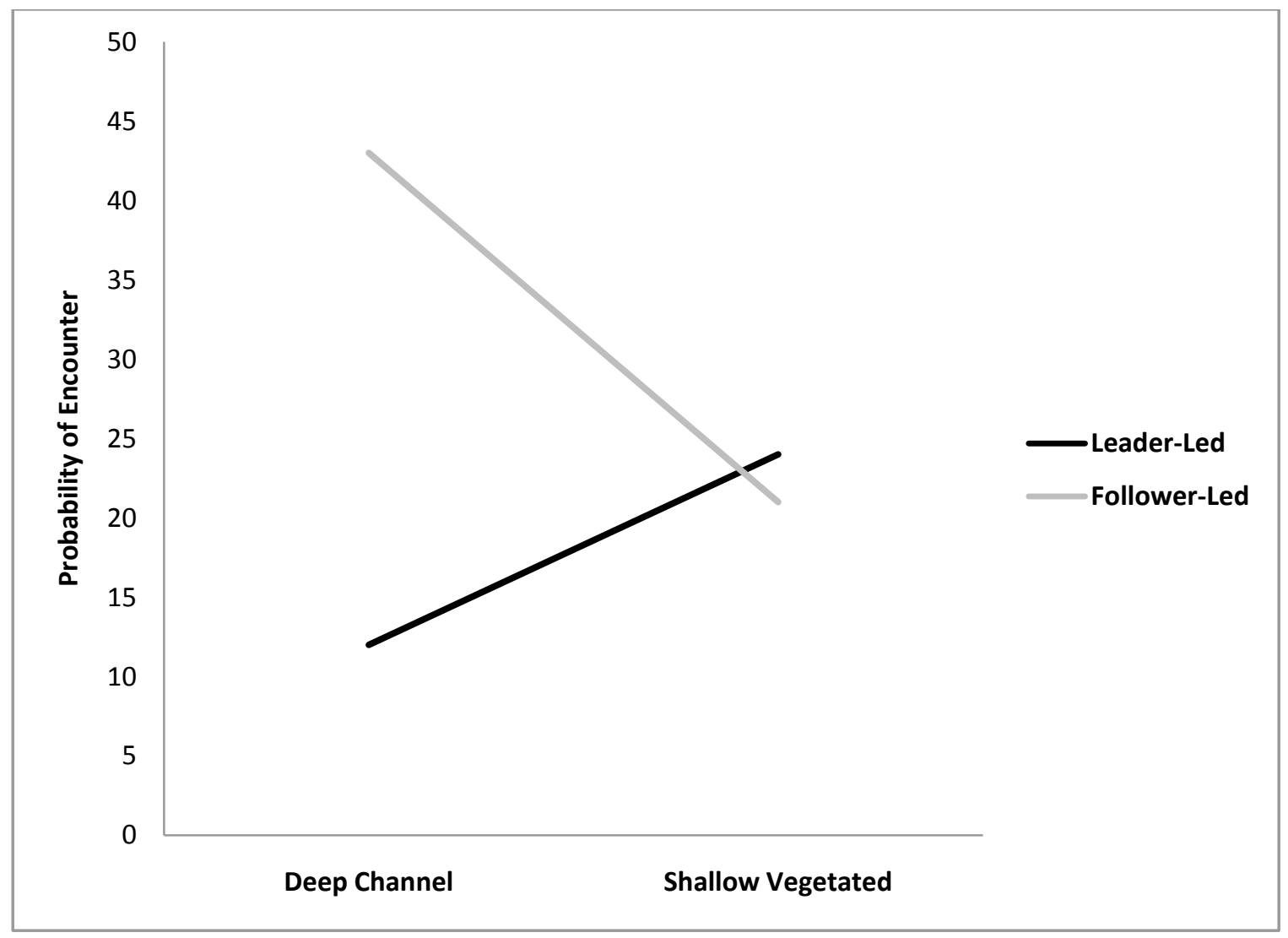

Figure 11. Probability of encounter for leader-led and follower-led groups in Man of War Harbor (MOW) benthic habitats (shallow vegetated and deep channel). Only shallow vegetated and deep channel habitats were available in MOW. Shallow vegetated habitat has more potential biomass of dolphin prey $($ mean $=95.1 \mathrm{~g} / \mathrm{hr}, \mathrm{SD}=95.5)$, compared to deep channel habitat $($ mean $=76.6 \mathrm{~g} / \mathrm{hr}, \mathrm{SD}=121.0)$. 


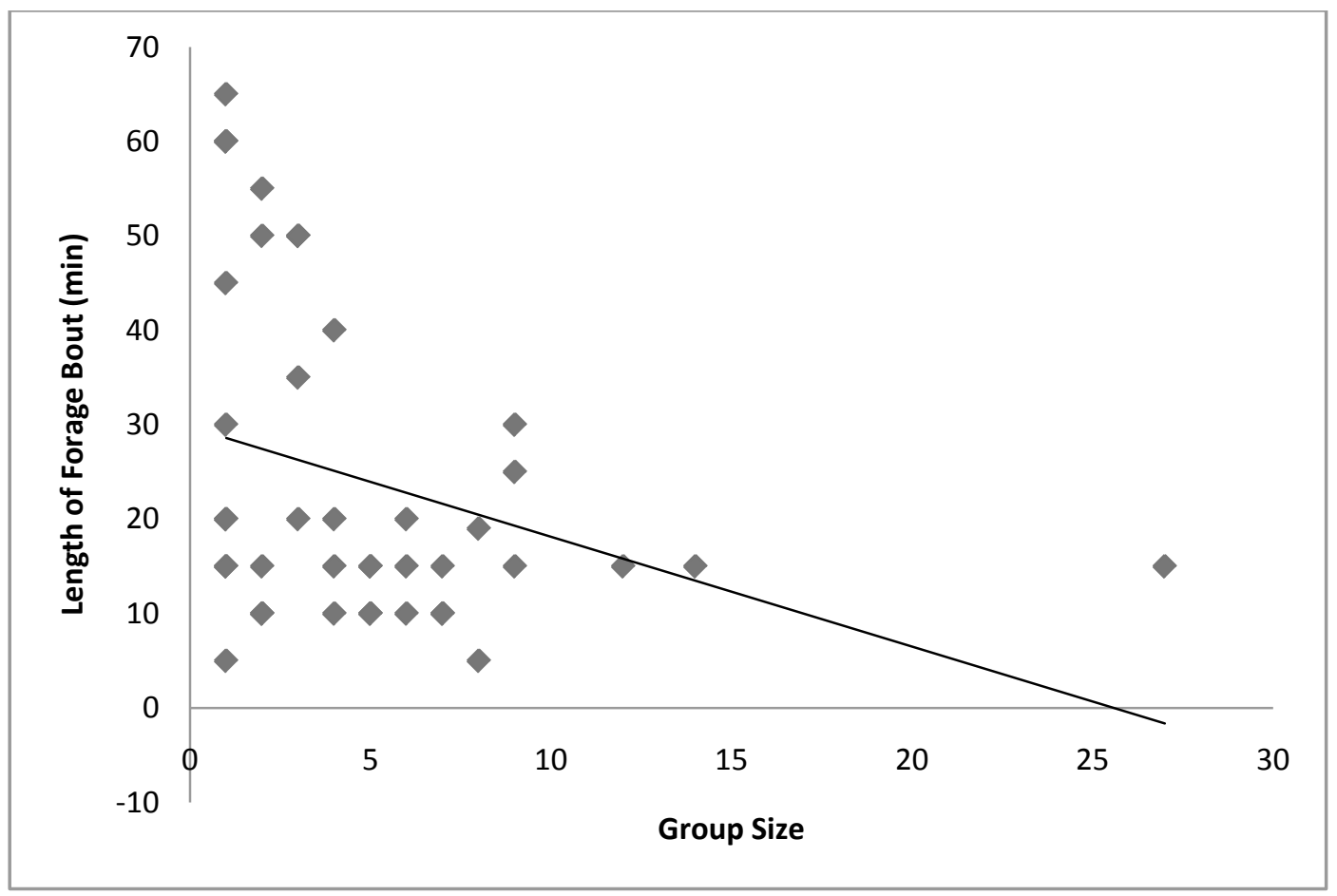

Figure 12. Association between length of foraging bouts and group size for bottlenose dolphins in the Lower Florida Keys $(\mathrm{n}=41$, $\mathrm{rs}=-0.34, \mathrm{p}=0.009)$. 


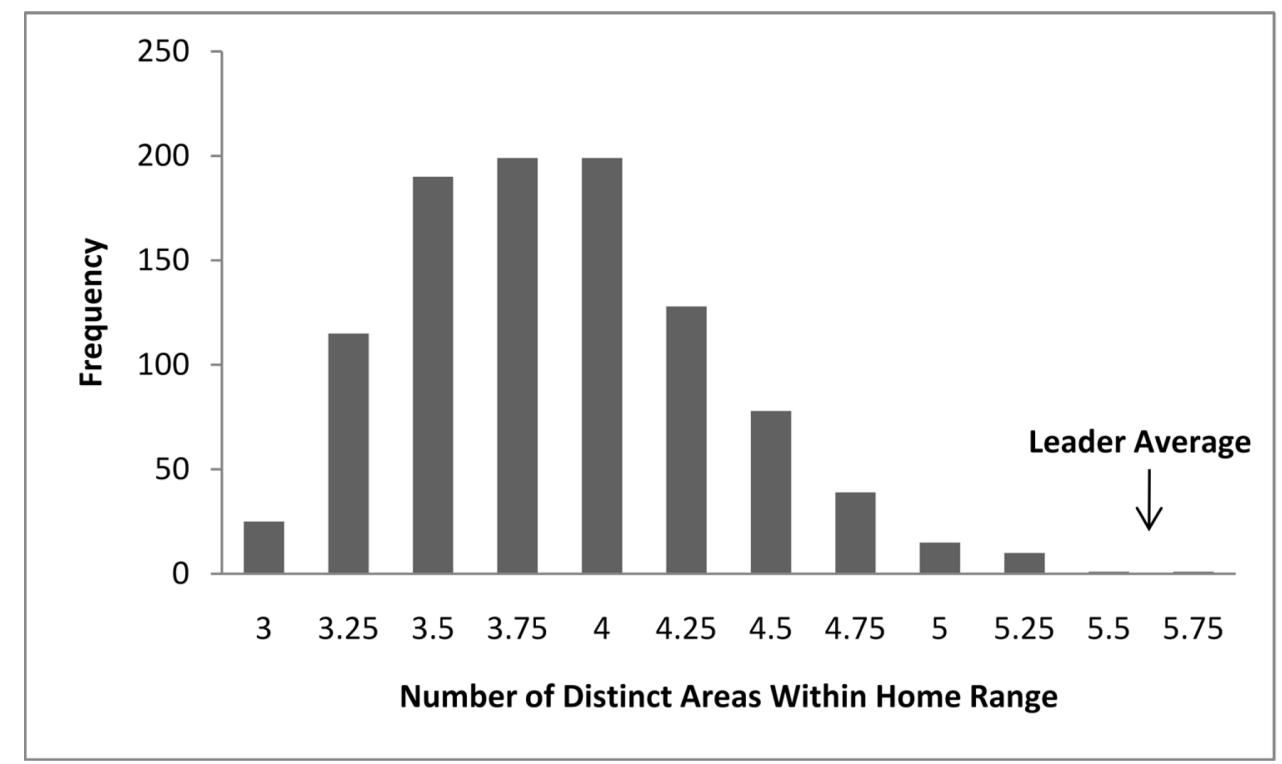

Figure 13. Frequency distribution for mean number of distinct areas within an individual home range ( $95 \%$ fixed kernel contour), created by random permutations of the actual data set for dolphins in the waters of the Lower Florida Keys (LFK), Florida. Distinct areas were defined as being separated by impassible area (by land or extreme shallows). LFK leaders (defined as having led groups more often than expected based on chance, Lewis, Chapter I), had more distinct areas within their home ranges than expected based on chance. 

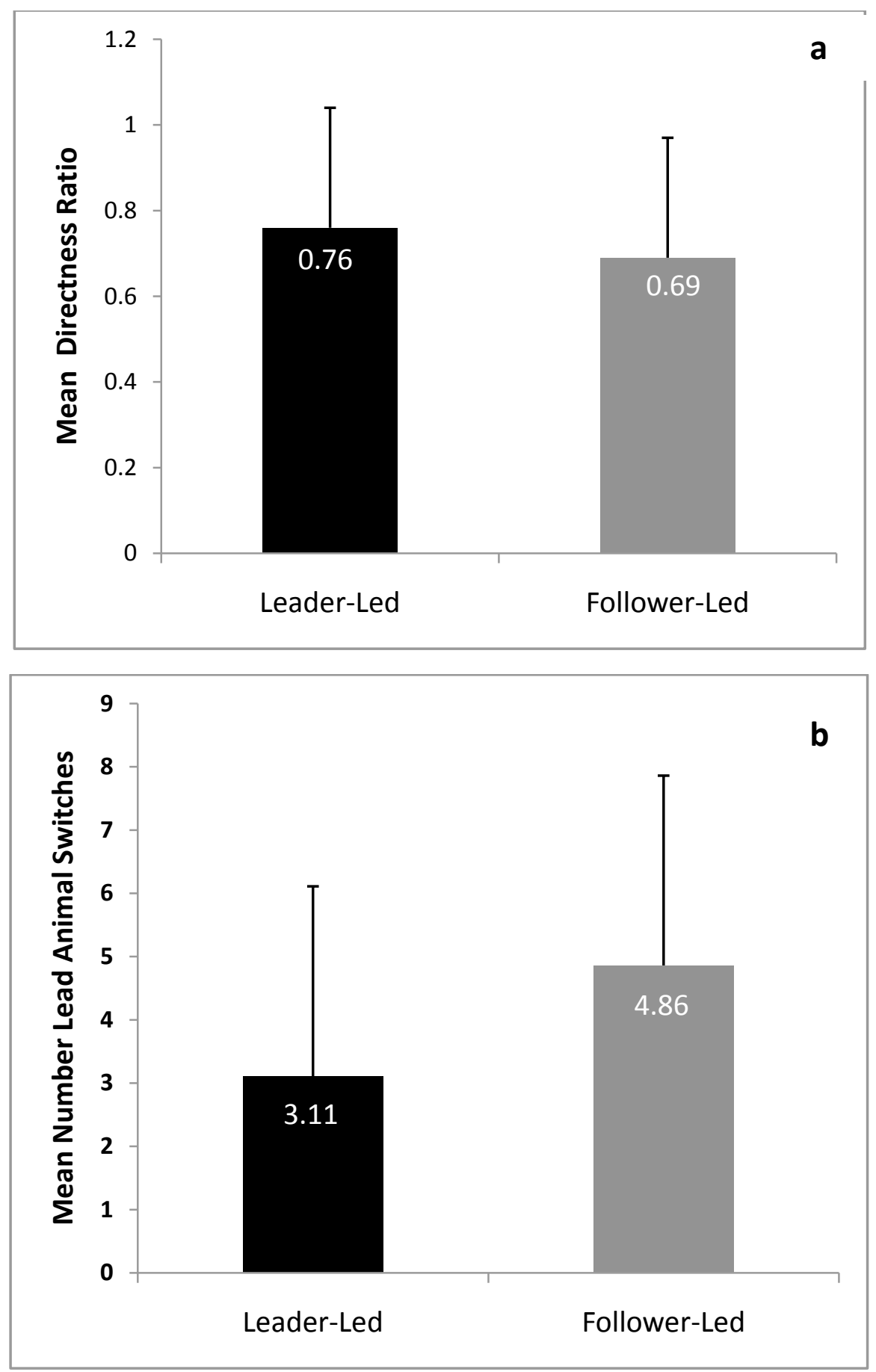

Figure 14 (a) and (b). Measures of travel efficiency for leader-led and follower led dolphin groups in the Lower Florida Keys. (a) Mean ratios of travel directness across $30 \mathrm{~min}$ (ratio $=$ sum of distances between each location noted every $5 \mathrm{~min}$ across the 30 min sample, divided by the straight line distance between the start and end points for the 30 min sample). (b) Mean number of lead animal switches (vanguard position) for dolphin groups. 


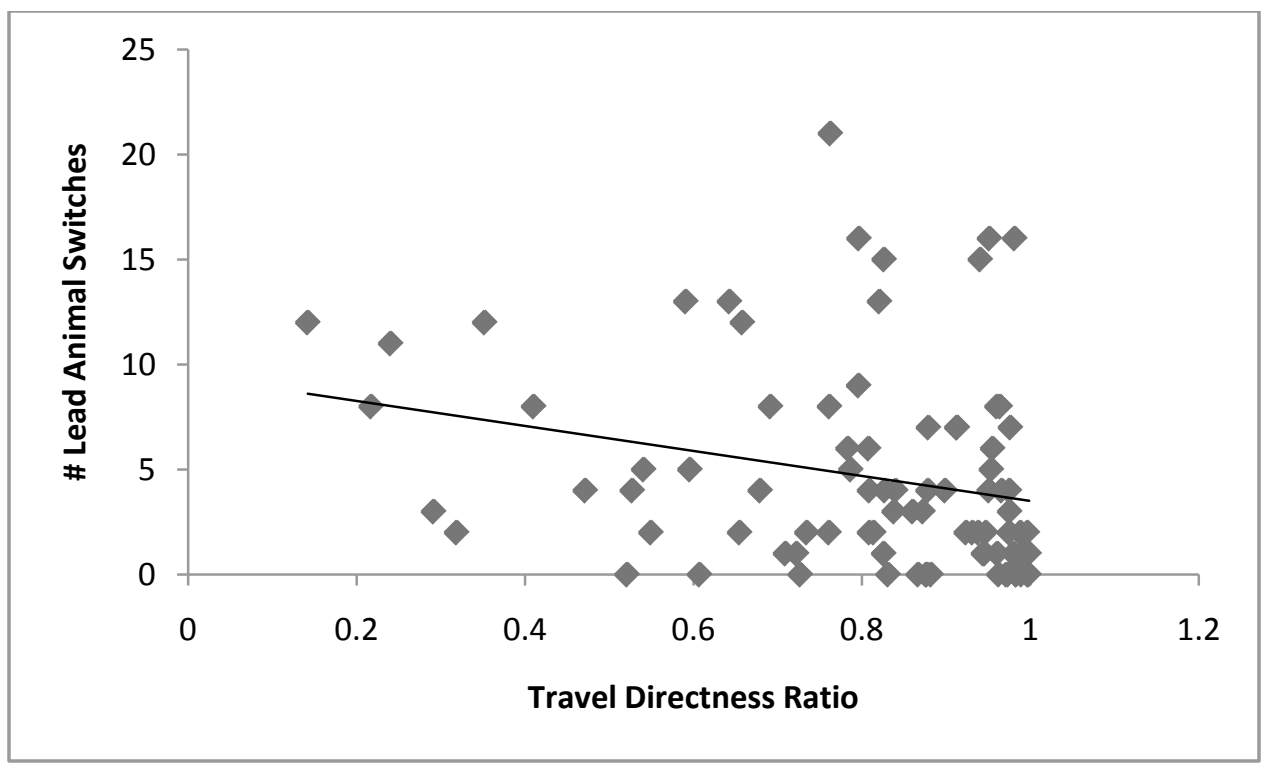

Figure 15. Association between number of changes in vanguard animal, and directness of paths taken when traveling for bottlenose dolphin groups $(n=86, r=-0.33, p=0.0001)$. 
CHAPTER V: INCLUSIVE FITNESS BENEFITS OF GROUP LEADING IN BOTTLENOSE DOLPHINS 


\begin{abstract}
In many species, particular individuals consistently lead group travel. While the benefits to followers often are relatively obvious, including access to water or food resources, unless groups are composed of close relatives the benefits to leaders can be unclear. This is especially true for species that feed on patchy mobile resources where group membership is not needed to gain access to these resources. All group members may locate them simultaneously and there is density dependent food intake. Leadership would be even less likely to occur under these circumstances in fission-fusion societies where individuals can choose whether or not they lead. Nonetheless, consistent leadership has been documented in a population of bottlenose dolphins (Tursiops truncatus) that meet these conditions. To test whether leaders might gain inclusive fitness benefits from leading I examined relatedness between leader-follower pairs. I found that the average relatedness value for leader-follower pairs was greater than expected $(p=0.003)$, and relatedness was positively correlated with association index values $\left(r_{s}=0.55, p<0.002\right)$. However, haplotypes were not frequently shared between leader-follower pairs $(21 \%)$. Together, these results suggest that bottlenose dolphin leaders gain inclusive fitness benefits by preferentially leading relatives, but these relatives are not siblings. These findings are somewhat surprising as recognition of relatives may not be easy in this species.
\end{abstract}

Key Words: bottlenose dolphin, division of labor, inclusive fitness, leadership, relatedness, Tursiops truncatus 


\section{INTRODUCTION}

In many social species, group travel is directed by a subset of individuals (e.g., Erhart and Overdorff 1999; Reebs 2000; Peterson et al. 2002; Stueckle \& Zinner 2008). Followers, which represent the majority of group members in most cases, can presumably benefit directly from location of resources by the leader(s). When leaders lead from a vanguard position, leaders can gain direct benefits through finders share (e.g., Bitetti and Janson 2001). However, when resources are mobile and patchy, it is just as likely that followers will locate resources at a time similar to the leader.

Specific individuals acting as leaders have been reported most often in stable groups (e.g., capuchins, Cebus sp., Di Bitetti \& Janson 2001; gray wolves, Peterson et al. 2002), but recent evidence indicates leadership can occur in highly dynamic fissionfusion species (changing group membership over hours and days) (Chapter II). Individuals in fission-fusion groups can choose whether to lead a group they have joined, to fall back and follow others in the group, or to exit and go alone if their needs and interest vary from other group members (group fission occurs when members differ in needs and desires). Because immediate benefits (e.g., food finds) are less likely an impetus to leading others, inclusive fitness benefits may provide reason for individuals in fission-fusion groups to provide leadership.

Seemingly altruistic behaviors can occur when the provider gains a less obvious benefit (e.g., inclusive fitness) (Hamilton 1964a, 1964b, Dugatkin 1997). These acts may be subtle, such as lowered aggression (e.g., Maher 2009), increased cooperation (e.g., Mitani et al. 2000, Ruch et al. 2009) or allowing for shared space use such as partial 
home range overlap (e.g., Ralls et al. 2001). Within social group-forming species, altruistic type behavior can appear to be more overt. For example, helping to care for young that are not direct progeny (e.g., Gero et al. 2008) or forming alliances to aid with the procurement of resources (e.g., Krutzen et al. 2003). In each of these cases, provider benefit is related to inclusive fitness. Leaders in fission-fusion groups may choose to lead relatives either through deciding which groups to join or by choosing whether or not to participate as leaders once they have joined.

To test if leaders benefit via inclusive fitness, I examined a population of bottlenose dolphins (Tursiops truncatus) in the Lower Florida Keys (LFK) where evidence for individuals acting as leaders has been documented (Chapter II). Bottlenose dolphin societies are highly dynamic fission-fusion, changing group membership frequently (occurring over hours and days) (Connor et al. 2000). To investigate the benefits of leading in fission-fusion groups, I examined relatedness within leaderfollower pairs in the LFK dolphin population.

\section{METHODS}

\section{Biopsy collection}

Skin samples were collected from 36 animals during 2008 in the Lower Florida Keys study area (Figure 1). Thirty-five of these were collected using a recurve crossbow (Barnett Wildcat III) with modified bolt tips (see Krützen 2002 for design of bolt tip). 
One sample was collected from a stranded animal. Tissue samples were stored in DMSO $(20 \%)$ until analysis.

\section{Mitochondrial DNA analysis}

Total genomic DNA was isolated from skin samples using Gentra Puregene DNA Extraction Kit (Qiagen). Five hundred base pairs (bp) of the mitochondrial control region were amplified via Polymerase Chain Reaction (PCR) using primers dlp1.5 and dlp5 (Baker et al. 1993). The reaction mixture (total reaction volume $=20 \mu 1)$ included $0.6 \mu 1$ of each primer, $0.4 \mu \mathrm{l} \mathrm{dNTPs}, 0.25 \mu 1 \mathrm{MgCl}_{2}, 2 \mu \mathrm{l}$ buffer, $0.05 \mu 1$ Taq polymerase (SigmaAldrich) and $1 \mu 1$ of template DNA. The PCR profile began with denaturization at $94^{\circ} \mathrm{C}$ for $3 \mathrm{~min}$, followed by 10 touched-down cycles of denaturization (30 sec), annealing (30 sec) and extension (1 min). Annealing temperature for touched-down cycles started at $63^{\circ} \mathrm{C}$ for cycle one, and ended at $53^{\circ} \mathrm{C}$ for cycle 10 . Touched-down cycles were followed with 21 regular cycles of $93^{\circ} \mathrm{C}$ for $30 \mathrm{sec}, 52^{\circ} \mathrm{C}$ for $30 \mathrm{sec}$, and $72^{\circ} \mathrm{C}$ for 1 min with a final extension at $72^{\circ} \mathrm{C}$ for $1 \mathrm{~min}$. Negative and positive controls were included in PCR runs and later used for validation of fragment amplification using 1.5\% agarose gel electrophoresis. Polymerase chain reacion products were cleaned using GenElute PCR DNA Purification Kit (Sigma), and then both forward and reverse primers were run through a cycle sequencing reaction using a Cycle Sequencing Ready Reaction Kit (Applied Biosystems). Ethanol precipitation was used to purify the products from the cycle sequencing. Strands were sequenced using an ABI 3730 DNA Sequencer (Applied 
Biosystems). Sequencing Analysis 5.2 was used to edit the sequences manually. Sequences were aligned using Lasergene SeqMan 7.0.

\section{Microsatellite analysis}

Each sample was genotyped at 26 loci (Table 1) using three Multiplex Polymerase Chain Reactions with labeled primers. The PCR's were carried out for each multiplex using a reaction mixture of $1 \mu 1$ of DNA template, $0.8 \mu 1$ of Primer Mixture (see Table 2), $4.0 \mu 1$ Master Mix (Qiagen) and $\mathrm{ddH}_{2} \mathrm{O}$ for a final reaction volume of 8.0 $\mu$ l. The PCR thermal cycle for multiplexes one and two included initial denaturation at $90^{\circ} \mathrm{C}$ for $15 \mathrm{~min}$, followed by 35 cycles of $95^{\circ} \mathrm{C}$ for $30 \mathrm{sec}, 60^{\circ} \mathrm{C}$ for $90 \mathrm{sec}$, and $71^{\circ} \mathrm{C}$ for $45 \mathrm{sec}$. A final extension followed at $71^{\circ} \mathrm{C}$ for $2 \mathrm{~min}$. The multiplex three PCR cycle differed only in the final extension which occurred at $60^{\circ} \mathrm{C}$ for $30 \mathrm{sec}$. Polymerase chain reaction products were sequenced on an ABI 3730 DNA Sequencer (Applied Biosystems). I determined allele size fragments using Gene Mapper 4.0.

Four loci (of the 26 original) were homogenous for all individuals sampled so they were discarded from further analysis. Eighteen loci (shaded in Table 2) passed tests for Hardy Weinberg equilibrium (HWE), linkage disequilibrium, and null alleles, (with Bonferroni corrections for multiple comparisons), and were used to calculate relatedness coefficients $\left(\mathrm{r}_{\mathrm{s}}\right)$ (Queller and Goodnight 1989) for individuals sampled. 


\section{Relatedness between Leader-Follower pairs}

Leaders were defined as individuals that led through position more than expected based on chance, and through successful direction change of the group (see Chapter II for further detail). Genetic data were available from 28 different leader-follower pairs in which the follower had followed that particular leader $\geq 2$ times. I determined an average $r_{s}$ value for these 28 pairs. This value was compared to the distribution of average $r_{s}$ values (using 28 randomly selected pairs), after 1000 random permutations of the entire data set (all $r_{s}$ values for the population sampled) to determine if the average for leaderfollower pairs was greater than expected via chance, and therefore indicating closer relatedness. A Generalized Estimating Equation (controlling for random effects of subject identity) was used to test if $r_{s}$ value or association index value (AI) (see description for calculation of AI below) predicted sharing of haplotypes between pairs.

\section{Leader-Follower Relatedness and Association Strength}

Association Indices (AI) were calculated for the LFK population using the Half Weight Index in SOCPROG (Whitehead 2009). Individuals used in the analysis had been sighted $\geq 5$ occasions. To determine if the resulting matrix was different from random, I calculated the $\mathrm{CV}$ for the observed matrix, and compared this value to those generated from 20,000 random permutations (shifting groups within samples) (Whitehead 1997; Bejder et al.1998) again using SOCPROG. The observed matrix was considered nonrandom if $>97.5 \%$ of the permuted matrices had $\mathrm{CV}$ values less than the $\mathrm{CV}$ from the observed matrix. Further testing for non-random associations (suggested by Whitehead 
2008) included examining the correlation value between the observed and randomly generated AI's, and also testing if $\mathrm{S}^{2} \times \mathrm{H}>5$, where $\mathrm{S}=$ social differentiation and $\mathrm{H}=$ average number of associations per individual (Whitehead 2008). For all leader-follower pairs, I tested the correlation between $r_{s}$ values and AI's using a Spearman Rank Test.

\section{RESULTS}

\section{Relatedness between Leader-Follower Pairs}

Leader-follower pairs had an average $r_{s}$ value greater than expected based on chance $($ mean $=0.13, \mathrm{SD}=0.16, \mathrm{p}=0.003)($ Figure 15$)$. Seven haplotypes were found among the sampled individuals. Only six $(21 \%)$ of the leader-follower pairs $(n=28)$ shared haplotypes. The number of haplotypes shared between pairs of leaders and followers was not significant $\left(X^{2}=20.4, d f=20, p=0.43\right)$. Relatedness value $\left(r_{s}\right)$ predicted sharing of haplotypes between leader-follower pairs $\left(X^{2}=28.03, \mathrm{df}=1, \mathrm{p}<0.001\right)$, while association index value did not.

\section{Leader-Follower Relatedness and Association Strength}

Our observed AI CV value, $(\mathrm{CV}=0.77, \mathrm{SD}=0.16)$ was significantly different from more than $95 \%$ of random matrices generated $(20,0000$ permutations, $p<0.01)$ (random generated $\mathrm{CV}=0.75, \mathrm{SD}=0.01$ ), indicating that associations in this population are not random. In addition $\mathrm{S}^{2} \mathrm{x} H$ was greater than $5\left(1.06^{2} \times 50.1=55.2\right)$ and $\mathrm{r}=0.48$. 
Association Index values were positively correlated with $r_{s}$ values for leader-follower pairs $\left(\mathrm{r}^{2}=0.55, \mathrm{p}<0.002\right)($ Figure 16$)$.

\section{DISCUSSION}

My findings provide support for the hypothesis that inclusive fitness may be a benefit to leaders in fission-fusion societies. I found that leader-follower pairs were more closely related to one another than the population at large, and these pairs associated frequently. This finding is somewhat surprising in a highly dynamic fission-fusion species because with frequent changes in group membership, it could be hard to determine who relatives are. Evidence for preferred associates that are closely related has been found in other fission-fusion species. For example, male Indian Ocean bottlenose dolphins (Tursiops aduncus) form alliances with closer relatives (Krützen et al. 2003), and African elephants (Loxodonta sp.) have group associations that correlate with relatedness (Archie et al. 2006). Frequency of associations (even though under flux) in the LFK may allow individuals to at least be aware of maternal siblings.

The LFK dolphin leaders may benefit by leading closer relatives to profitable resources (i.e., habitat with greater prey availability) where these followers may have increased chances of locating food. Knowledge of leaders may also provide greater safety to followers (e.g., avoidance of areas where stranding could occur, or where predation threat is larger). There are examples of leaders providing guidance to resource use. In another species of bottlenose dolphin (Tursiops aduncus), some dolphins provide cues for when to stop and start feeding results from knowledge of area depletion (Lusseau 2007). 
Leaders in African elephant groups have also been documented to provide guidance to resources learned many years prior (McComb et al. 2001). Because bottlenose dolphins are a fission-fusion type species, they have the ability to choose associates. Leaders can choose to go alone (though decision making different from interests of other group members), follow (by allowing others to control movement choice and falling behind), or to lead others (by making movement decisions which others follow). Having and making the choice to lead specific individuals (closer relatives) indicates that benefits to these leaders should result from these interactions. Correlations between association indices and relatedness values have been found in many species (e.g., African elephants, Archie et al. 2006; sperm whales, Physeter macrocephalus, Gero et al. 2008; Indian Ocean bottlenose dolphins, Möller et al. 2006). Whereas not related to leadership, these associations were considered in response to some inclusive fitness benefits.

Whereas relatedness values based on genomic DNA were greater than expected for leader-follower pairs, the lack of shared haplotypes suggests that pairs were frequently not related maternally. Some cetaceans, e.g., Orcinus orca (Bigg et al. 1987), and Globicephala macrorhynchus (Kasuya and Marsh 1984), form matrilineal groups but these species have relatively stable group membership (lower levels of fission-fusion) compared to bottlenose dolphin, and groups include male and female offspring. With frequent changes in group membership for bottlenose dolphins, it was not expected that groups would be necessarily bond through a strict matrilineal society. Still matriarchal bonds were still possible. Matriarchal societies have been documented in one terrestrial fission-fusion species, the African Elephant (McComb et al. 2001), but none from marine species with highly dynamic fission-fusion, including the bottlenose dolphin. My finding 
that genomic relatedness predicted the sharing of haplotypes between leader-follower pairs, is not unexpected, because individuals sharing haplotypes share genomic DNA. The combined results however, indicate that the leader-follower groupings in the LFK are not merely the result of always following maternal relatives.

Results of this study suggest that relatedness is an important predictor for leadership of specific followers in the LFK bottlenose dolphin population. It will be of interest to determine whether similar findings can be made for other populations of this species, (and other fission-fusion species) particularly in relation to the parameters of the population (e.g., size and residential nature) and the environment (heterogenous vs. homogenous) where they are found. Additionally, while there are theories for how individuals might determine who relatives are (e.g., vocalizations, chemosensory) no conclusive tests have been conducted yet in cetaceans. Future research (potentially of captive dolphins) where relatives are housed in the same facility might be useful here. Having the ability to determine who ones relatives are and then leading these individuals may be another benefit to leaders in highly dynamic fission-fusion societies, increasing inclusive fitness for these individuals. 


\section{ACKNOWLEDGMENTS}

This research was supported through funding from Sigma Xi, Project Aware, and Harbor Branch Oceanographic Institute Protect Wild Dolphins Grant. J Lewis was supported while conducting this research and writing this manuscript by Florida International University's Dissertation Acquisition and Dissertation Year Fellowships. Logistical and in kind support was given through NOAA Key West, NMFS Virginia Key, NMFS Pascagoula, Key West City Marina, and many volunteers. Special thanks to Corinne Ackermann and Anna Kopps (University of Zürich) for assistance in the lab, and to the Evolutionary Genetics Group at the University of Zürich, for providing lab space, equipment and training. Data were collected under NMFS Permit No. 779-1633, NMFS LOC No. 572-1639 and FIU IACUC No. 07-003. 


\section{REFERENCES}

Archie, E. A., Moss, C. J., \& Alberts, S. C. (2006). The ties that bind: Genetic relatedness predicts the fission and fusion of social groups in wild African elephants.

Proceedings of the Royal Society B: Biological Sciences, 273(1586), 513.

Bejder, L., Fletcher, D., \& Bräger, S. (1998). A method for testing association patterns of social animals. Animal Behaviour, 56(3), 719-725.

Bigg, M. A., \& Andrew, M. (1987). Killer whales: A study of their identification, genealogy and natural history in British Columbia and Washington state Phantom Nanaimo, BC, Canada.

Connor, R., Wells, R., Mann, J., \& Read, A. (2000). The bottlenose dolphin: Social relationships in a fission-fusion society. Cetacean Societies: Field Studies of Dolphins and Whales, 91-126.

Di Bitetti, M. S., \& Janson, C. H. (2001). Social foraging and the finder's share in capuchin monkeys, Cebus apella. Animal Behaviour, 62(1), 47-56.

Dugatkin, L. A. (1997). Cooperation among animals: An evolutionary perspective Oxford University Press, USA.

Erhart, E. M., \& Overdorff, D. J. (1999). Female coordination of group travel in wild Propithecus and Eulemur. International Journal of Primatology, 20(6), 927-940.

Gero, S., Engelhaupt, D., \& Whitehead, H. (2008). Heterogeneous social associations within a sperm whale, Physeter macrocephalus, unit reflect pairwise relatedness. Behavioral Ecology and Sociobiology, 63(1), 143-151.

Giraldeau, L. A., \& Caraco, T. (2000). Social foraging theory Princeton University Press.

Hamilton, W. D. (1964). The genetical evolution of social behavior, parts 1 and 2. Journal of Theoretical Biology, 7, 1-52.

Hoelzel, A., Potter, C., \& Best, P. (1998). Genetic differentiation between parapatric'nearshore'and'offshore'populations of the bottlenose dolphin. Proceedings of the Royal Society B: Biological Sciences, 265(1402), 1177.

Kasuya, T., \& Marsh, H. (1984). Life history and reproductive biology of the shortfinned pilot whale, Globicephala macrorhynchus, off the Pacific coast of Japan. Report of the International Whaling Commission, Special, 6, 259-310. 
Krützen, M., Barré, L. M., Möller, L. M., Heithaus, M. R., Simms, C., \& Sherwin, W. B. (2006). A biopsy system for small cetaceans: Darting success and wound healing in Tursiops spp. Marine Mammal Science, 18(4), 863-878.

Krützen, M., Sherwin, W. B., Connor, R. C., Barré, L. M., Van de Casteele, T., Mann, J., and R. Brooks (2003). Contrasting relatedness patterns in bottlenose dolphins (Tursiops sp.) with different alliance strategies. Proceedings of the Royal Society of London.Series B: Biological Sciences, 270(1514), 497.

Krutzen, M., Valsecchi, E., Connor, R., \& Sherwin, W. (2001). Characterization of microsatellite loci in Tursiops aduncus. Molecular Ecology Notes, 1(3), 170-172.

Maher, C. R. (2009). Effects of relatedness on social interaction rates in a solitary marmot. Animal Behaviour, 78:925-933.

McComb, K., Moss, C., Durant, S. M., Baker, L., \& Sayialel, S. (2001). Matriarchs as repositories of social knowledge in African elephants. Science, 292(5516), 491-494.

Mitani, J. C., Merriwether, D. A., \& Zhang, C. (2000). Male affiliation, cooperation and kinship in wild chimpanzees. Animal Behaviour, 59(4), 885-893.

Möller, L. M., Beheregaray, L. B., Allen, S. J., \& Harcourt, R. G. (2006). Association patterns and kinship in female indo-pacific bottlenose dolphins (Tursiops aduncus) of southeastern Australia. Behavioral Ecology and Sociobiology, 61(1), 109-117.

Natter, A. 2007. New microsatellite markers in orangutans (Pongo sp.) and bottlenose dolphins (Tursiops sp.), University of Zurich, Zurich.

Peterson, R. O., Jacobs, A. K., Drummer, T. D., Mech, L. D., \& Smith, D. W. (2002). Leadership behavior in relation to dominance and reproductive status in gray wolves, Canis lupus. Canadian Journal of Zoology, 80(8), 1405-1412.

Queller, D. C., \& Goodnight, K. F. (1989). Estimating relatedness using genetic markers. Evolution, 43(2), 258-275.

Ralls, K., Pilgrim, K. L., White, P., Paxinos, E. E., Schwartz, M. K., \& Fleischer, R. C. (2001). Kinship, social relationships, and den sharing in kit foxes. Journal Information, 82(3)

Reebs, S. G. (2000). Can a minority of informed leaders determine the foraging movements of a fish shoal? Animal Behaviour, 59(2), 403-409.

Ruch, J., Lisa, H., Trine, B., \& Jutta, S. Relatedness facilitates cooperation in the subsocial spider, Stegodyphus tentoriicola. BMC Evolutionary Biology, 9 
Shinohara, M., Domingo-Roura, X., \& Takenaka, O. (1997). Microsatellites in the bottlenose dolphin Tursiops truncatus. Molecular Ecology, 6(7), 695-696.

Stueckle, S. (2008). To follow or not to follow: Decision making and leadership during the morning departure in chacma baboons. Animal Behaviour, 75(6), 1995-2004.

Valsecchi, E., \& Amos, W. (2008). Microsatellite markers for the study of cetacean populations. Molecular Ecology, 5(1), 151-156.

Whitehead, H. (1997). Analysing animal social structure. Animal Behaviour, 53(5), 10531067.

Whitehead, H. (2008). Precision and power in the analysis of social structure using associations. Animal Behaviour, 75(3), 1093-1099.

Whitehead, H. (2009). SOCPROG programs: analyzing animal social structures. Behavioral Ecology and Sociobiology. 63: 765-778. 
Table 2. Primers used in three separate multiplexes for polymerase chain reactions.

Primers shaded in gray are those that provided useful results (i.e., successfully amplified, passed tests of Hardy Weinberg Equilibrium, linkage analysis and null alleles) and were used in relatedness analyses.

${ }^{a}$ Natter 2008, ${ }^{b}$ Krutzen et al. 2001, 'Shinohara et al. 1997, ${ }^{\mathrm{d}}$ Hoelzel et al. 1998,

${ }^{\mathrm{e}}$ Valsecchi and Amos 1996

\begin{tabular}{|c|c|c|c|}
\hline Primer & Multiplex No. & Primer & Multiplex No. \\
\hline Tur4_98 & 1 & Tur4_141 ${ }^{\mathrm{a}}$ & 2 \\
\hline Tur4_117 & 1 & $\mathrm{D} 8^{\mathrm{a}}$ & 2 \\
\hline$M K 6^{\mathrm{b}}$ & 1 & Tur4_162 ${ }^{\mathrm{a}}$ & 3 \\
\hline $\mathrm{E} 12^{\mathrm{a}}$ & 1 & Tur4_132 & 3 \\
\hline Tur4_108 & 1 & Tur4_80 & 3 \\
\hline Tur4_66 & 1 & Tur4_142 & 3 \\
\hline Tur4_105 & 1 & Tur4_153 ${ }^{\mathrm{a}}$ & 3 \\
\hline Tur4_128 & 1 & $\mathrm{MK} 9^{\mathrm{b}}$ & 3 \\
\hline Tur4_11 ${ }^{\mathrm{a}}$ & 1 & $M K 5^{\mathrm{b}}$ & 3 \\
\hline $\mathrm{D} 22^{\mathrm{c}}$ & 2 & KWM12d & 3 \\
\hline Tur4_138 & 2 & $\mathrm{EV} 37^{\mathrm{e}}$ & 3 \\
\hline Tur4_91 ${ }^{\mathrm{a}}$ & 2 & $\mathrm{MK}^{\mathrm{b}}$ & 3 \\
\hline Tur4_87 & 2 & $\mathrm{MK} 8^{\mathrm{b}}$ & 3 \\
\hline
\end{tabular}




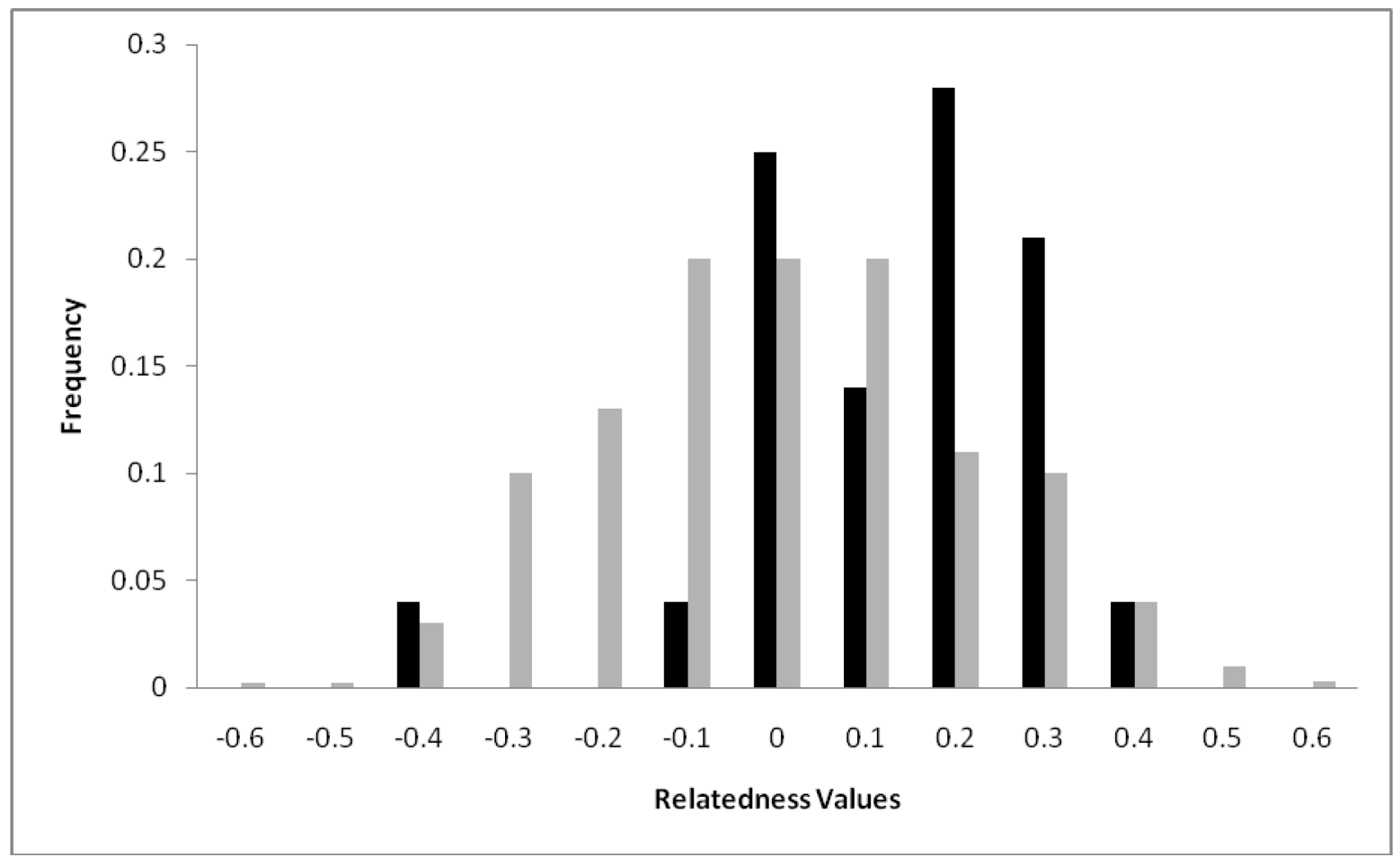

Figure 16. Frequency of pair-wise relatedness values (Queller and Goodnight 1989) for leader-follower pairs (black bars) and for all pairs that were sampled (gray bars). 


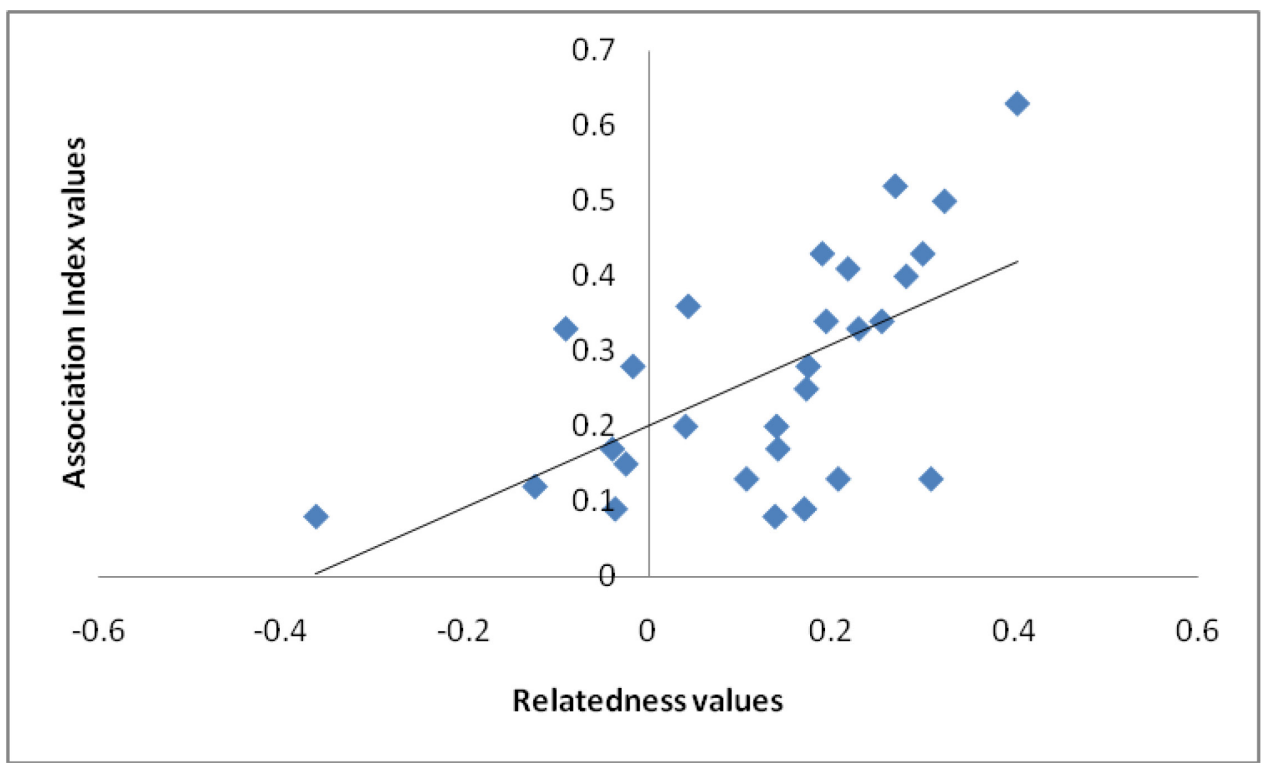

Figure 17. Association Index values (Half-Weight Index) plotted against relatedness values (Queller and Goodnight 1989) for leader -follower dolphin pairs in the Lower Florida Keys ( $\mathrm{rs}=0.55, \mathrm{p}<0.002)$. 
CHAPTER VI: CONCLUDING REMARKS 
My dissertation research provides the first evidence for consistent leadership when traveling in a highly dynamic fission-fusion species. Research findings indicated that leaders in LFK bottlenose dolphin groups are those with greater habitat knowledge, and followers benefit from this knowledge through increased access, or efficient travel to profitable areas. The LFK leaders likely gain fitness benefits by leading kin.

Finding evidence for leadership in the LFK population (Chapter II) expands the current knowledge about the grouping systems in which leadership would be expected to occur (i.e., unstable in addition to stable). Leading by specific individuals is unexpected in fission-fusion groups because group members typically do not interact regularly and therefore individuals would not be able to identify others with greater knowledge. Leadership in LFK dolphins likely results from 1) a need to follow specific individuals to effectively access profitable habitat and 2) a small localized population characterized by frequent associations between the same individuals. Future studies on other fission-fusion species with similar social and ecological conditions are likely to identify other cases of leadership.

Study of leadership in a highly dynamic fission-fusion population provided a way to investigate why group members followed specific individuals, because various conditions could be compared within one population (with constantly changing group membership). For example, I could compare differences between group types (leader-led vs. follower-led) within the same population. Examining different types of groups, I was able to determine that predictability for locating leader-led vs. follower-led groups was related to habitat type (Chapter IV). Leader-led groups also moved more directly when 
traveling when compared with follower-led groups. These results indicate that followers benefit from leader area knowledge or area familiarity. Evidence for larger area familiarity for leaders was found examining leader home ranges and measures of centrality within the LFK social network (Chapters III and IV). Leaders used more distinct areas and had larger measures of centrality (gained by associations in areas not shared by other associates).

While followers benefit from leader knowledge, leaders could benefit by leading closer relatives. Leaders in LFK dolphin groups do not profit from "finders share" as leaders do in other environments. Dolphin prey in the LFK is patchy and mobile, so there is an equal chance for any group member to locate fish as they forage. Instead I found that leaders profited through kinship with followers (Chapter V). Genetic relatedness values for leader-follower pairs were greater than expected from chance.

Finally, results from this dissertation provide the first evidence from the field that following specific leaders provides more efficient travel. First, the number of leaders in a group remained low regardless of group size (Chapter II). Secondly, I found that when experienced individuals led groups (leader-led), vanguard animals switched less often, (which correlated with more direct travel) (Chapter IV). Both of these tactics can be beneficial because the fewer individuals attempting to lead, the less time and energy may be wasted deciding which way to move.

Information gained by this work, expands our knowledge about leadership use in animal societies. We now know consistent leadership can occur in a broader range of species with more varied social structure than originally expected. Significant insights 
were made regarding how using leadership benefits group members (leaders and followers), allowing us to see why leadership would be used at all within groups. In addition, results of this dissertation increased the information available on bottlenose dolphin societies. I found that females may play a more important role in the social structure of this species than originally understood and that a small subset of individuals with more central positions within the larger social network may have a large influence on the well-being of the population.

By providing these insights, further questions have developed which may be important towards expanding the study of leadership in animal groups in the future. Of particular interest, 1) Leadership was found under the conditions in the LFK for bottlenose dolphins, but would it be found under other circumstances (e.g., more homogenous habitat) for this species or others (marine or terrestrial) with fission-fusion grouping elsewhere? and 2) Certain aspects about how leadership was used in the study species (such as keeping number of leaders low) indicated that there may be some optimum conditions for use of leadership in fission-fusion groups. Examination of the conditions of leadership using mathematical models may provide insight to allow further testing using field data.

Study of leadership is important because at its core, it provides the mechanism behind why groups developed in the first place. For a group to remain intact, individuals have to follow other individuals. Because of this detail, as this field of study develops further it will likely provide information that will help us to better understand group optimally and the mechanisms for efficient travel by groups. 
VITA

JENNIFER S. LEWIS

April 20, 1968

1991-1996

1997-2002

2003-2009

2008-2009

2009-2010

2003-2010
Born in Monroe, Louisiana

B.S. Biology, San Diego State University, San Diego, CA

M.S. Marine Science, University of Alabama, Tuscaloosa, AL

Teaching Assistant for General Biology and Ecology Labs, Florida International University, Miami, FL

Dissertation Evidence Acquisition Fellow Florida International University, Miami, FL

Dissertation Year Fellow, Florida International University, Miami, FL

Doctoral Candidate, Biology, Florida International University, Miami, FL

\section{PRESENTATIONS:}

(November 2009): Response of bottlenose dolphins to disturbance by vessel traffic mirrors sub-lethal reactions to natural predators. Marine Mammal Society Meeting, Quebec City, CA.

(August 2008): Does use of leadership lend towards efficiency of movement? Animal Behavior Society Meeting, Snowbird, Utah.

(October 2007): Movement in bottlenose dolphins. Florida Keys Sanctuary Advisory Council Meeting, Key Largo, FL

(July 2007): Multiple behavioral tactics are useful when traveling. Animal Behavior Society Meeting. Burlington, VT. 


\section{PUBLICATIONS:}

Lewis, J. and W. Schroeder. (2003). Mud Plume Feeding; a unique foraging behavior of the bottlenose dolphin in the Florida Keys. Gulf of Mexico Science. 21(1): 92-97.

Lewis, J. (2002). Behavioral comparison of two populations of the bottlenose dolphin (Tursiops truncatus) in Florida waters. M.S. thesis. University of Alabama, Tuscaloosa, AL.118pp.

Bartimus, J., Kepper, J. and Nyden, B. (1994). Sweetwater Marsh Crab Survey. An Annual Report to the California Department of Transportation. 12pp. 